Cognitive diversity in a healthy aging cohort:

Cross-domain cognition in the Cam-CAN project

\begin{abstract}
Objectives: Studies of "healthy" cognitive aging often focus on a limited set of measures that decline with age. The current study argues that defining and supporting healthy cognition requires understanding diverse cognitive performance across the lifespan.
\end{abstract}

Methods: Data from the Cambridge Centre for Ageing and Neuroscience (Cam-CAN) cohort was examined across a range of cognitive domains. Performance was related to lifestyle including education, social engagement, and enrichment activities.

Results: Results indicate variable relationships between cognition and age (positive, negative, or no relationship). Principal Component Analysis indicated maintained cognitive diversity across the adult lifespan, and that cognition-lifestyle relationships differed by age and domain.

Discussion: Our findings support a view of normal cognitive aging as a life-long developmental process with diverse relationships between cognition, lifestyle and age. This reinforces the need for large-scale studies of cognitive aging to include a wider range of both ages and cognitive tasks.

Keywords: healthy aging, cognitive function, principal components analysis, lifestyle, cognitive reserve 


\section{HEALTHY COGNITIVE AGING}

Cognitive diversity in a healthy aging cohort:

Cross-domain cognition in the Cam-CAN project

We all want to age healthily, and while a growing literature examines how we can achieve "successful" cognitive aging (Daffner, 2010; Depp, Harmell, \& Vahia, 2011; Hartley et al., 2018; Saint Martin et al., 2017), there is no clear definition of what we mean by success. Frequently, large-scale studies of aging implicitly or explicitly define successful cognitive aging as the absence of age-related pathologies, so that identifying or supporting success focusses on avoiding or reversing pathological cognitive declines in later life (e.g., Li et al., 2008). This approach provides little understanding of cognitive aging independent of pathology and decline; a better understanding of normal cognitive aging is important for changing our expectations and stereotypes about aging, for providing the basis for sound evidence-based policy development, and for developing targeted interventions to support lifelong cognitive health. The current study presents data from the Cambridge Centre for Ageing and Neuroscience project (CamCAN; www.cam-can.com), a study of healthy neurocognitive development across the adult lifespan. The Cam-CAN dataset includes measures of general cognitive health, but also includes a range of cognitive experiments which are sensitive to normal as opposed to pathological age-related changes. We report here on a wide range of cognitive measures extracted from the Cam-CAN dataset and examine how diverse cognitive assessment in a cohort study improves our understanding of normal cognitive aging.

Many large-scale studies of cognitive aging either include only older participants (Deary, Gow, Pattie, \& Starr, 2012; Ganguli et al., 2010; Gerstorf, Ram, Hoppmann, Willis, \& Schaie, 2011; Kobayashi, Wardle, Wolf, \& von Wagner, 2015; Miller et al., 2010; Saint Martin et al., 2017) or primarily assess 


\section{HEALTHY COGNITIVE AGING}

cognitive domains that reliably decline with age, such as episodic memory or executive function (e.g., Bielak, Gerstorf, Anstey, \& Luszcz, 2014; Deary et al., 2012; Lindenberger \& Ghisletta, 2009; Salthouse, 2010b; Seeman et al., 2011; Singh-Manoux et al., 2012). The theoretical aim of these studies is often to identify commonalities across a range of cognitive processes that decline with age, in order to characterise a single or small number of "domain-general" factors underpinning age-related cognitive decline (Lindenberger \& Ghisletta, 2009; Salthouse \& Ferrer-Caja, 2003). This "singlefactor" or domain-general approach is associated with the dedifferentiation hypothesis which posits that with increasing age, cognitive processes become more monolithic and less well-specified. This change is reflected in the predictions that age leads to increased intercorrelation between cognitive abilities (e.g., Hülür, Ram, Willis, Schaie, \& Gerstorf, 2015), and an increase in the proportion of individual variation in cognitive performance that can be explained by domain-general processes (Hultsch, MacDonald, \& Dixon, 2002; Lindenberger \& Baltes, 1997; Lindenberger \& Ghisletta, 2009; Wilson et al., 2002). The current study will examine whether a "single-factor" account is supported when including an atypically diverse set of cognitive measures, and whether a domain-general factor accounts for more variance in older adults' performance compared to younger adults'.

In contrast to many large-scale studies, domain-specific experimental studies suggest that normal aging has a complex effect on cognitive function. First, there is ample evidence that the relationship between age and performance varies across cognitive domains (e.g., Park et al., 2002), with age-related decline seen in some domains such as fluid intelligence (Salthouse, 2009; Salthouse \& Ferrer-Caja, 2003), while others are relatively preserved or even improve, including language comprehension, vocabulary and general knowledge (Burke \& Shafto, 2008; Salthouse, 2009, 2010b; Salthouse \& Ferrer-Caja, 2003; Thornton \& Light, 2006; Verhaeghen, 2003). Second, even in domains where performance declines with age, impairments often reflect specific rather than general cognitive processes. This can be seen in the 


\section{HEALTHY COGNITIVE AGING}

relationship of age to language function, where age is commonly found to impair aspects of language production such as word retrieval, while most core comprehension processes are preserved (Burke \& Shafto, 2008; Shafto \& Tyler, 2014). Moreover, while older adults have more word retrieval failures than younger adults, the age effect reflects a specific rather than general impairment in word production: While phonological access during production weakens with age, the underlying phonological representations remain intact (Burke, MacKay, Worthley, \& Wade, 1991; Burke \& Shafto, 2008; L. E. James \& Burke, 2000), as do other production processes such as semantic access (J. K. Taylor \& Burke, 2002). Finally, cognitive aging is a life-long developmental process including both linear and nonlinear changes across the adult age range (Salthouse, 2009). Even abilities such as word retrieval that are reliably worse in older adults decline gradually across the adult lifespan, rather than when adults reach “old age” (Shafto, Burke, Stamatakis, Tam, \& Tyler, 2007), a point raised across other domains by Salthouse (2009). Taken together, evidence from smaller-scale experiments suggest that large-scale studies examining "healthy," "normal," or "successful” cognitive aging should (1) examine performance across the adult lifespan, and (2) use a cross-domain range of cognitive measures that are (3) designed to identify specific mechanisms of normal age-related variance.

\section{Current study: Aims and objectives}

The current study builds on the findings of experimental cognitive aging research to ask whether we can demonstrate the same diversity within a cohort study, and if this benefits our understanding of normal cognitive aging. We employ the Cam-CAN dataset, which combines general measures of cognitive health with domain-specific experiments that tap into normal rather than pathological variability (see Shafto et al., 2014 for a full description of the project protocol). The current study presents data from 21 cognitive tasks that (1) reflect a range of cognitive domains including memory, language, emotion processing, attention/executive function, face processing, motor/speed, and crystallized knowledge; (2) 


\section{HEALTHY COGNITIVE AGING}

measure abilities that typically decline with age (e.g., episodic memory) as well as those that remain stable or improve across the lifespan (e.g., sentence comprehension); and (3) reflect both domaingeneral processes (e.g., fluid intelligence) and domain-specific processes (e.g., emotion regulation).

Our first aim is to examine the range of relationships between age and cognitive performance in the Cam-CAN dataset, including 24 cognitive measures from 21 tasks across 7 cognitive domains. Our second aim is to use Principal Components Analysis (PCA) to summarize these age-cognition relationships across cognitive domains. We use PCA in order to strike a balance between maintaining as diverse a set of measures as possible while still providing summary measures that can reveal crossdomain components where they exist. Compared to other data reduction methods (such as Latent Variable Analysis) PCA components reflect all sources of variance in the data (e.g., Costello \& Osborne, 2005), but PCA can still test for whether underlying components reflect both domain-general and domain-specific processes which may differ or be equivalent across age groups. We use PCA across all participants, and also within sampling deciles, to test for the possibility that a dominant component will account for more variance in older than younger adults (a prediction of the dedifferentiation hypothesis).

Our third aim is to ask whether an atypically diverse assessment of cognitive performance has relevance for understanding the relationships between lifestyle and cognition. In keeping with a pathological view of aging, previous studies of lifestyle measures have focused on later life, and on how lifestyle choices help prevent or ameliorate cognitive decline (Clare et al., 2017; Marioni et al., 2012; Opdebeeck, Martyr, \& Clare, 2016). There is less focus on cognition in younger or middle-aged adults, and little attention to cognitive abilities that do not decline with age. The current study examines the relationship between cognitive performance and three lifestyle variables: education, social engagement, and enrichment activities (including both physical activity and other activities such as reading or pursuing 


\section{HEALTHY COGNITIVE AGING}

hobbies). The relationship of these variables to cognitive function has been examined individually, and they are all related to the concept of cognitive reserve, the ability for older adults to be resilient to neural decline and maintain cognitive abilities (Chan et al., 2018; Chapko, McCormack, Black, Staff, \& Murray, 2017; Clare et al., 2017; M. J. Valenzuela et al., 2012; M. J. Valenzuela \& Sachdev, 2007). Previous research provides evidence for better cognitive outcomes in old age with higher education (Chapko et al., 2017; Clare et al., 2017; Marioni et al., 2012; Matthews, Marioni, \& Brayne, 2012; Opdebeeck et al., 2016), higher levels of social engagement (Bielak et al., 2014; Bourassa, Memel, Woolverton, \& Sbarra, 2017; Clare et al., 2017; B. D. James, Wilson, Barnes, \& Bennett, 2011; Seeman et al., 2011), and higher levels of enrichment activities such as physical activity (Bielak et al., 2014; Clare et al., 2017) reading (Bielak et al., 2014; Clare et al., 2017), pursuing hobbies (Bielak et al., 2014), attending classes (Opdebeeck et al., 2016), or playing games (Clare et al., 2017; Jonaitis et al., 2013; Opdebeeck et al., 2016).

Although hypothesized contributors to cognitive reserve include measures from early adulthood (e.g., education) and midlife (e.g., occupational experience), studies often focus on cognitive outcomes in later life, i.e., how cognitive reserve acquired throughout life affects late life cognition (Chan et al., 2018; Chapko et al., 2017; M. Valenzuela, Brayne, Sachdev, \& Wilcock, 2011). In order to expand this approach to include cognitive performance in younger and middle-aged participants, we use lifestyle measures that reflect participants' current levels of social engagement and enrichment activities. However, we include a measure of educational attainment from early adulthood because education is a critical measure of cognitive reserve. Education often provides the most robust predictions of cognitive processing (Chapko et al., 2017; Opdebeeck et al., 2016), even being used as a standalone measure of cognitive reserve (Meng \& D’Arcy, 2012; M. J. Valenzuela \& Sachdev, 2006). Key questions in the current study include how the relationships between cognition and lifestyle may differ (1) across age 


\section{HEALTHY COGNITIVE AGING}

groups, (2) between cognitive measures reflecting domain-general and domain-specific cognitive processes, and (3) between cognitive measures that decline or are maintained across the adult lifespan.

\section{Methods}

\section{Cam-CAN project: Recruitment, testing stages, and data repository}

In this study we report a subset of the full Cam-CAN dataset, so this section provides an overview of the project in order to contextualize the findings. The initial Cam-CAN data collection consisted of 3 stages: An interview (Stage 1) in which participants provided demographic, health and lifestyle, and core cognitive measures in person and via a self-completed questionnaire; Detailed cognitive testing and core measures of brain structure and function (Stage 2) completed in testing sessions at the Medical Research Council Cognition and Brain Sciences Unit in Cambridge, UK (MRC-CBSU); And, in-depth cognitive neuroscience tasks (Stage 3) also completed at the MRC-CBSU. Data reported here are taken from Stages 1 and 2.

Participants were recruited into Stage 1 from the Cambridge, UK community via their general practitioner (GP) surgeries. Green et al. (2018) provides details about recruitment and exclusion, where out of 7616 eligible participants who were initially approached, 2680 (35.2\%) were ultimately interviewed. Active refusals such as being too busy ( $61 \%$ of refusals; $\mathrm{N}=3008)$ and illness $(35.6 \%$ of refusals; $N=1756$ ) made up the majority of refusals at this stage. Green et al. (2018) examined several factors affecting participation including gender, age, and deprivation. Key findings included no main effect of gender, evidence that middle-aged participants were more likely to volunteer than younger or older participants, and the finding that deprivation affected participation, especially in older adults.

Of the 2680 participants interviewed at Stage 1, 709 went on to participate in Stage 2 (this stage had a planned N of 700). Recruitment into Stage 2 excluded participants with contraindications for MRI, low 


\section{HEALTHY COGNITIVE AGING}

Mini Mental State Examination scores (MMSE; Folstein, Folstein, \& McHugh, 1975; low scores were 24 or lower), poor hearing (failing to hear $35 \mathrm{~dB}$ at $1000 \mathrm{~Hz}$ in either ear), poor vision (below 20/50 on the Snellen vision test, Snellen, 1862), poor English (non-native or non-bilingual English speakers), selfreported substance abuse, serious health conditions, or serious psychiatric conditions such as psychosis. Based on these exclusion criteria, 1528 participants were ruled out of participation in Stage 2 during the Stage 1 interview via computer algorithm. A further 233 were excluded due to active refusal $(\mathrm{N}=130)$, illness $(\mathrm{N}=11)$, a change in circumstances such as moving from the area $(\mathrm{N}=76)$, or having missing information $(\mathrm{N}=16)$. Finally, 210 participants did not move forward to Stage 2 because they were surplus to the sampling requirements (oversampled).

Further information about the recruitment, exclusion criteria, and contents of the testing stages can be found in Shafto et al. (2014), Taylor et al. (2017) and Green et al. (2018). Further details of exclusion and refusals in Stage 1 can be found in Green et al. (2018) and in Stages 2 and 3 can be found in Schweizer et al. (2019). Further details on the contents of the Cam-CAN data repository and information on how to access it can be found in Taylor et al. (2017) or at cam-can.com.

\section{Participants}

Participants were an $\mathrm{N}=708$ subgroup who completed detailed cognitive testing (Stage 2). Participants were recruited into Stage 2 equally across gender within seven sampling deciles (18-27, 28-37, 38-47, 48-57, 57-68, 68-77, 78+). Table 1 provides a summary of participant sample sizes, gender, and highest educational attainment across the deciles. While age is used as a continuous variable in the main analyses, to improve interpretation of the results some analyses and visualizations divide the group either into sampling deciles (1-7) or three broader age groups: a younger group including deciles 1-3 $(\mathrm{R}=18-47, \mathrm{M}=35.13, \mathrm{~N}=278)$, a middle-aged group including deciles 4-5 $(\mathrm{R}=48-67, \mathrm{M}=57.62, \mathrm{~N}=212)$, and an older group including deciles 6-7 $(\mathrm{R}=68-88, \mathrm{M}=76.63, \mathrm{~N}=218)$. 


\section{HEALTHY COGNITIVE AGING}

\section{Materials}

\section{Cognitive tasks}

All tasks reported here were either completed as part of an initial interview and questionnaire (Stage 1) or as part of subsequent cognitive testing sessions (Stage 2). The 21 cognitive tasks used in the current study are listed in full in Supplemental Table 1. The methodological details for most of these tasks are provided in Shafto et al. (2014) with the exception of the Spot the Word task, described by Baddeley and colleagues (Baddeley, Emslie, \& Nimmo-Smith, 1993), and the "Story Memory" task which was taken from the logical memory test portion of the Weschler Memory Scale Third UK Edition (WMS-III UK; Weschler, 1999). The 21 tasks reflect 7 cognitive domains (Attention/Executive function, Language, Emotion processing, Memory, Motor/Speed, Face processing, and Crystallized Knowledge), and provide 53 variables overall (between 1 and 9 variables per task).

Six tasks across three cognitive domains were selected to represent processes typical of studies of cognitive aging where performance declines with age. These Typically Declining tasks are indicated in Supplemental Table 1 and consist of Fluid Intelligence, Choice Response Time (RT) and Verbal Fluency from the executive functions domain, Simple RT from the processing speed domain, and Visual Short Term Memory (VSTM) Capacity and Story Memory from the memory domain. While not inclusive of all tasks used in studies of single-factor or domain-general cognitive aging, these were chosen from the available dataset as commonly used in large-scale studies of cognitive aging (e.g., Deary et al., 2012; Salthouse, 2009; Salthouse \& Ferrer-Caja, 2003).

\section{Lifestyle measures}

Social engagement was assessed using three self-report questions about current social activities including how often participants (1) see their relatives, (2) attend clubs or social groups, and (3) see their 


\section{HEALTHY COGNITIVE AGING}

neighbors. These questions were the same as those examined by Clare et al. (2017) and the questions and scoring strategy were similar to other previous studies (Ang, 2018; Bourassa et al., 2017; Clare et al., 2017). Each question was scored on a 3-point scale so that total scores ranged from 0-9. Current enrichment activities were assessed in a version of the Life Experience Questionnaire (LEQ; M. J. Valenzuela \& Sachdev, 2007) which was modified for use on the Cam-CAN project. The LEQ asks participants about a broad range of life experiences, which include experiences from their current life, and for middle-aged and older adults, retrospective reporting of activities from previous life stages. On this questionnaire, enrichment activities are assessed in a subscale of the LEQ that queries 7 aspects of recent life experience: (1) domestic and international travel, (2) outings to see family and friends, (3) reading, (4) playing musical instruments, (5) artistic pursuits, (6) speaking a second language, and (7) mild, moderate, and vigorous physical activities. Responses for each of these 7 domains were scored on a 5-point scale, so that enrichment activities scores ranged from 0-35 ${ }^{1}$. The measure of education used was highest qualification achieved by standard exams, GSCE/GCE/CSE, A-levels, or university degree (see Table 1).

Procedure

\section{Cognitive tasks}

Participants completed the cognitive tasks during Stages 1 and 2 of the Cam-CAN project. All participants were offered all cognitive tasks with the following exceptions: Emotional Memory,

\footnotetext{
${ }^{1}$ While the question about outings to see family and friends bears some similarity to social engagement questions, we included this question to retain the integrity of the LEQ subscale score; subsequent analyses revealed little correlation between the social engagement and enrichment activities measures (see Results and Supplemental Table 5).
} 


\section{HEALTHY COGNITIVE AGING}

Emotional Reactivity and Regulation, Motor Learning, and Force Matching. These tasks were only offered to half of the participants because versions of Emotional Memory and Emotional Reactivity and Regulation were included in Stage 3 of the project and participants could not repeat these tasks for methodological reasons. Participation in these tasks was counterbalanced across decile and gender groups, and tasks that were not offered to all participants are not included in PCAs.

\section{Lifestyle Measures}

Responses for education and social engagement were given as part of the Stage 1 interview, which was conducted in the participant's home or another place of their choosing (such as their workplace). Responses for enrichment activities were collected from a questionnaire on lifestyle and health that participants completed prior to their interview which included the LEQ.

\section{Analysis overview}

We addressed our research aims in three analysis stages: (1) First, to establish the range of relationships between age and cognitive performance in the Cam-CAN dataset, we conducted within-task regressions to examine the different relationships between age and 24 cognitive measures across 7 cognitive domains. Given evidence for nonlinear age effects on cognitive performance (e.g., Salthouse, 2009) we included both linear and quadratic expressions of age in regression analyses. (2) Second, to provide a summary of these age-cognition relationships and test predictions of single-factor models we conducted a Cross-domain PCA using a subset of 17 measures (those that were offered to all participants) across the 7 cognitive domains. We tested a key prediction of dedifferentiation by examining variance explained by the components in Cross-domain PCAs within sampling deciles. We also compared the results of the Cross-domain PCA to a Typically Declining PCA which included the six Typically Declining cognitive measures. (3) Finally, to examine how lifestyle relates to diverse cognitive 


\section{HEALTHY COGNITIVE AGING}

assessment, we used regression to relate factor scores from the Cross-domain and Typically Declining

PCAs to lifestyle variables. These regressions included interaction terms with age, and significant interactions with age were followed up with regression analyses within younger, middle-aged and older age groups in order to aid with interpretation. Analyses were conducted in SPSS version 25 (IBM, New York, USA).

Results

\section{Cognitive Measures}

A total of 53 variables from 21 tasks are summarized in Supplemental Table 1, with each task contributing between 1 and 9 dependent variables. For the 13 tasks with multiple dependent variables we used PCA to create summary measures: Variables for these tasks were entered into PCAs, with separate PCAs used where tasks had substantively different stages or response instructions (e.g., separate summary measures were created for the Emotional Memory task "priming", "recognition" and "recall" variables). Factors with eigenvalues greater than one were used as cognitive measures for that task, and in all cases a single-factor solution was produced. All cognitive measures were standardized and the resulting 24 measures are listed in Supplemental Table 1 (see also Table 2). These cognitive measures were used in all subsequent analyses.

\section{Within-task regressions: Age and cognitive measures}

Results of regression analyses relating linear and nonlinear expressions of age to cognitive measures are presented in Table 2, and plots of the relationships between age and each cognitive measure are shown in Supplemental Figure 1. The results indicate a wide range of effect sizes (we used Cohen $\mathrm{F}^{2}$ and the conventional values of small effect $=.02$, medium effect $=.15$, large effect $=.35$ ) for effects of age $\left(\right.$ Cohen $\mathrm{F}^{2}=<.01-.79$, Median $\left.=.14\right)$ and $\operatorname{age}^{2}\left(\right.$ Cohen $^{2}=<.01-.85$, Median $\left.=.16\right)$. All of the 


\section{HEALTHY COGNITIVE AGING}

Typically Declining measures revealed worse performance for older than younger adults, including Fluid Intelligence, Verbal Fluency, Choice RT, VSTM Capacity, Story Memory and Simple RT. Most measures were associated with a quadratic expression of age: while five measures showed evidence of only a linear relationship with age (Choice RT, Priming, Recall, Motor Learning, and Balance Test), a quadratic expression of age was significantly related to scores for sixteen measures including two measures with the highest scores in middle age (Picture Naming and Familiar Faces).

\section{Cross-domain PCA}

In order to provide a cross-domain summary of age-cognition relationships, seventeen cognitive measures across 7 cognitive domains (see Supplemental Table 1) were included in a Cross-domain PCA using varimax rotation. We retained four factors which accounted for $51.42 \%$ of the total variance, based on having eigenvalues greater than one and confirmation using scree plots. The eigenvalues and variance explained by each factor as well as the loadings for each factor on the 17 measures are given in Supplemental Table 2 .

Factor 1 most strongly reflects the Fluid Intelligence measure, and the label of "Fluid Abilities" is applied because of this and because of the widespread loadings across a number of tasks requiring fluid abilities including VSTM Capacity and Verbal Fluency. Linear and quadratic expressions of age were related to factor scores, and as can be seen in Table 3 and Figure 1, the factor scores for the Fluid Abilities are lower for older ages.

Factor 2 loads on a number of tasks which require processing and naming of visually-presented materials, including proper name production (Familiar Faces, TOTs) and object naming (Picture Naming). This "Naming" factor is related to the quadratic expression of age (see Table 3) where the direction of the relationship between age and the factor score reverses after the third decile (see Figure 


\section{HEALTHY COGNITIVE AGING}

1). This reversal is reflected in a positive correlation between factor scores and age for participants under age $50(\mathrm{r}=.25, \mathrm{p}<.001)$, but a negative correlation from age 50 and over $(\mathrm{r}=-.52, \mathrm{p}<.001)$.

Factors 3 and 4 add little in interpretive power compared to their underlying measures as they load on only two (Factor 3) or one measure (Factor 4). Factor 3 clearly reflects Crystallized Abilities as measured by the Spot the Word and Proverb tasks, and Factor 4 simply provides a version of the Sentence Comprehension measure orthogonalized to the other factors, and had an eigenvalue only slightly above 1 (1.19). The Crystallized Abilities factor is related positively to age (see Figure 1 and Table 3), and the Sentence Comprehension factor scores are unrelated to age. While the sparse loadings on Factors 3 and 4 do not provide strong evidence about the underlying dimensionality of this dataset, we retain these factor scores as useful summary measures reflecting the range of cognition-age relationships (see Supplemental Figure 1). ${ }^{2}$

\section{Cross-domain PCA by decile}

In order to examine evidence for age-related increases in the variance explained by the first principal component (a prediction of the dedifferentiation hypothesis), the Cross-domain PCA was repeated within each decile, restricting the analysis to four factors so as to provide the best comparison with the PCA across all participants. Supplemental Table 4 presents the explained variance for each factor in

\footnotetext{
${ }^{2}$ Given the range of relationships between age and factor scores, we used confirmatory factor analysis (CFA) to verify that similar cognitive measures loaded on the same factors in young, middle-aged and older age groups (configural invariance). The details of this analysis are provided in the Supplemental Materials. We also used multi-group CFA to test for differences in factor loadings across age groups (measurement invariance; see Supplemental Materials and Supplemental Table 3 for results).
} 


\section{HEALTHY COGNITIVE AGING}

each decile. There was some variability across the deciles in the variance explained by each factor (Factor $1 \mathrm{R}=14.24 \%-17.89 \%$; Factor $2 \mathrm{R}=10.22 \%-14.11 \%$; Factor $3 \mathrm{R}=9.82 \%-12.93 \%$; Factor 4 $\mathrm{R}=8.78 \%-12.01 \%$ ), but there were no systematic relationships between variance explained and age groups.

\section{Typically Declining PCA}

For comparison with the Cross-domain PCA, the Typically Declining PCA was conducted including only the six typically declining cognitive measures: Fluid Intelligence, Choice RT, Verbal Fluency, Simple RT, VSTM Capacity, and Story Memory. The results indicated one factor with an eigenvalue greater than one, accounting for $48.43 \%$ of the total variance (See Supplemental Table 2 for details of the PCA).

Loadings were moderate to strong across all six input measures, with the strongest loading for Fluid Intelligence (.86). As can be seen in Table 3, the Typically Declining factor scores have a strong negative relationship with age. Finally, as with the Cross-domain PCA, the Typically Declining PCA was repeated within each decile. Supplemental Table 4 provides the explained variance for the singlefactor result in each decile, and as with the Cross-domain PCA while there was some variability $(\mathrm{R}=31.89 \%-39.18 \%)$, there was no systematic relationship with age.

\section{Regressions relating lifestyle and age to cognition}

The final set of analyses related cognitive factor scores to lifestyle measures, including (1) highest education attainment, (2) social engagement, and (3) enrichment activities. Supplemental Table 5 shows the correlations between these variables and age, demonstrating that the older age groups had lower education attainment $(\mathrm{r}=-.25, \mathrm{p}<.01)$, higher social engagement $(\mathrm{r}=.35, \mathrm{p}<.01)$, and lower levels of enrichment activities ( $\mathrm{r}=-.17, \mathrm{p}<.01)$. Amongst the lifestyle measures, levels of social engagement and 


\section{HEALTHY COGNITIVE AGING}

enrichment activities are not correlated ( $\mathrm{p}>.10)$, but higher education is associated with lower social engagement $(r=-.09, \mathrm{p}<.05)$ and higher enrichment activities $(r=.33, p<.01)$. The relationship between education and social engagement does not survive in a partial correlation controlling for age $(\mathrm{r}=.002$, $\mathrm{p}=.95$ ), but even when age is controlled for, higher education is associated with higher levels of enrichment activities $(\mathrm{r}=.30, \mathrm{p}<.01)$.

Lifestyle measures were entered into five regressions along with gender, age, and age interaction terms, predicting factor scores for each of the four Cross-domain cognitive factors and the Typically Declining factor. In all regression models, continuous predictors were mean-centered to avoid multicollinearity and improve interpretation of interactions with age. To account for multiple tests, a Bonferroni correction was used so that we report regression analyses with $\mathrm{F}$ values significant at the $\mathrm{p}<.01$ level (see Table 4). Evidence for interactions with age were followed up by repeating regression analyses within younger, middle-aged, and older age groups. To account for multiple tests, a Bonferroni correction was used so that we report regression analyses with $\mathrm{F}$ values significant at the $\mathrm{p}<.02$ level (see Supplemental Table 6).

Table 4 shows the results of regressions across all age groups, which indicate a range of relationships between cognitive factors and lifestyle measures. Factor scores for Fluid Abilities were higher for participants with higher education attainment and enrichment activities, regardless of age, while the relationship of Fluid Abilities to social engagement depended on age. To follow up the interaction of age and social engagement, the regression was repeated within younger, middle-aged, and older age groups. Results revealed that social engagement was negatively related to Fluid Abilities factor scores for young participants $(\beta=-.24, p<.01)$, but not middle-aged or older participants (middle-aged: $\beta=.01$, $\mathrm{p}=.93$; older $\beta=.09, \mathrm{p}=.39 ;$ see Supplemental Table 6). 


\section{HEALTHY COGNITIVE AGING}

The regression with Naming factor scores revealed no main effects of lifestyle measures, but there were significant interactions of age with social engagement and enrichment activities. Follow up regressions within age groups demonstrated that the effect of social engagement was numerically strongest for younger adults $(\beta=.14, p=.12)$, weaker for middle-aged adults $(\beta=.11, p=.28)$, and weakest for older adults $(\beta=-.07, p=.53)$. The effect of enrichment activities did not reach significance within any age group either, but was numerically negative for younger adults $(\beta=-.09, p=.32)$ and middle-aged adults $(\beta=-.04, p=.71)$, and positive for older adults $(\beta=.05, \mathrm{p}=.64)$.

The Crystallized Abilities factor scores were higher for participants with higher educational attainment and social engagement, and there were also age interactions with educational attainment and enrichment activities. Within age group regressions indicated that higher educational attainment had a significant effect on Factor 3 scores for all age groups, but was strongest for older adults (young: $\beta=.31, p<.01$; middle-aged: $\beta=.47, p<.01 ;$ older $\beta=.75, p<.01)$. The effect of enrichment activities was only significant for younger participants $(\beta=.17, \mathrm{p}<.05)$.

The Sentence Comprehension factor scores were not significantly related to lifestyle factors, but was the only factor to demonstrate an effect of gender, with higher factor scores for females compared to males, $(\beta=.20, \mathrm{p}<.01)$. However, the regression analysis was not significant when corrected for multiple tests (see Table 4).

Finally, the Typically Declining factor was only related to educational attainment, such that participants with higher factor scores had higher educational attainment, with no evidence of interactions with age.

\section{Discussion}

The current study provides an overview of normal cognitive performance across the adult lifespan and across multiple cognitive domains. While a single-factor view was supported if using only a subset of 


\section{HEALTHY COGNITIVE AGING}

typically declining measures, a Cross-domain PCA identified both domain-general and domain-specific components, with factor scores that variably were lower, higher, or the same in older age groups. The Cross-domain PCA repeated within sampling deciles did not support the dedifferentiation hypothesis prediction that a dominant component will account for more variance in older than younger adults. This provides evidence that cognitive diversity is maintained across the lifespan, despite the decline in many of the cognitive measures (see also de Mooij, Henson, Waldorp, Kievit, \& Kievit, 2018 for similar results from the Cam-CAN cohort). These results highlight the importance for large-scale studies of "healthy", "normal" or successful cognitive aging to recruit participants across the adult lifespan and include a range of cognitive measures that tap into normal as well as pathological variability.

\section{Lifestyle measures: Implications for identifying risks and interventions}

Evidence from the lifestyle measures suggests that there is variability in the specific relationships of lifestyle measures to cognitive factors scores: Education, social engagement, and enrichment activities had distinct relationships with the cognitive measures and differential interactions with age. Critically, lifestyle variables not only related to the domain-general Fluid Abilities factor, but related to three of the four Cross-domain cognitive factors, including Crystallized Abilities, where scores improved across the adult lifespan. Likewise, lifestyle measures were not only related to cognitive performance in older adults, but in some cases the relationships were strongest for younger adults, or existed across age groups.

Educational attainment related robustly to Fluid Abilities and Crystallized Abilities, in keeping with previous evidence that higher education has a reliable effect on cognitive abilities, possibly stronger than other measures of cognitive reserve (Chapko et al., 2017; Opdebeeck et al., 2016). However, the relationship of cognition to education was not the same across the lifespan for all aspects of cognition; for example, education was most strongly related to Crystallized Abilities for older adults. Importantly, 


\section{HEALTHY COGNITIVE AGING}

these interactions with age would be missed if we had focused only on the Typically Declining factor, where scores related to education but did not interact with age.

Although education predicted cognitive performance robustly, both social engagement and enrichment activities also demonstrated independent relationships to cognition, and again these would be missed with a focus only on the Typically Declining factor. Social engagement and enrichment activities have both been suggested as potential targets of interventions to support cognitive abilities in later life (Bielak et al., 2014; Bourassa et al., 2017; Clare et al., 2017; B. D. James et al., 2011; Marioni et al., 2014), with very few studies of aging including a younger group (but see Borgeest, Henson, Shafto, Samu, \& Kievit, 2018; Seeman et al., 2011). The current results suggest that while social engagement relates to Crystallized Abilities across the lifespan, younger adults' cognition was most strongly related to social engagement for the Fluid Abilities and Naming factors. What is perhaps less expected is that increased social engagement is associated with lower factor scores in Crystallized Abilities and, for younger adults below age 40, lower factor scores for Fluid Abilities. These results suggest that higher levels of social engagement are not universally related to better cognitive performance in the current cohort. Thus, when considering risks for cognitive decline or potential interventions to support cognition, the type of cognitive process and time of life must both be considered. The relationship between cognition and lifestyle measures may depend not only on the nature of the cognitive processes and type of support, but also upon the current level of cognitive processing and the relevance of different behaviors during different life stages.

\section{Multidimensional successful cognitive aging: Implications for models and interventions}

The reported results support a more multidimensional view of normal cognitive aging than is typical of large-scale studies. The within-task regressions revealed relationships between performance and age that varied in both their strength and the nature of the effect. For example, and in keeping with previous 


\section{HEALTHY COGNITIVE AGING}

findings, while Fluid Intelligence is lower for older adults than younger adults (Salthouse, 2009;

Salthouse \& Ferrer-Caja, 2003), Sentence Comprehension scores do not differ across the age range (Tyler et al., 2010), and Spot the Word scores are higher for older adults than younger adults (Salthouse \& Ferrer-Caja, 2003; Verhaeghen, 2003). In keeping with the more targeted experiments included in the Cam-CAN project, age effects differed within domain as well; for example, in the Language domain Picture Naming is lowest for older adults but Sentence Comprehension did not differ across the age groups.

The Cross-domain PCA demonstrated that the Fluid Abilities factor explained the most variance and was markedly lower in old age (Lindenberger \& Ghisletta, 2009; Salthouse \& Ferrer-Caja, 2003). While the strong relationship between age and the Fluid Abilities factor is in keeping with single-factor or domain-general accounts of aging, the diverse relationships between the other factors and age suggests that definitions of "healthy", "normal", or "successful" cognitive aging should not stop at the examination of typically declining or fluid abilities. Cognitive performance underpinned by the other factors (Naming, Crystallized Abilities, and Sentence Comprehension) did not decrease monotonically across age groups, but still represent critical everyday cognitive function. These and other processes should be accounted for in models of successful cognitive aging.

Similarly, when identifying markers or developing interventions to support cognition, results from the Cam-CAN cohort highlight the need for a lifespan, targeted approach that builds on strengths as well as seeking to ameliorate decline. First, lifestyle variables may relate to cognition across the lifespan: for example, Crystallized Abilities scores were related to enrichment activities only in younger adults. Second, lifestyle variables may relate to specific rather than general aspects of cognition: for example, neither social engagement nor enrichment activities related to the Typically Declining factor (but see Bielak et al., 2014; Clare et al., 2017; Seeman et al., 2011), but related to domain-specific processes 


\section{HEALTHY COGNITIVE AGING}

(such as Naming). Similarly, while the effect of education interacted with age in relating to Crystallized Abilities, there was no age interaction in the relationship of education and Typically Declining factor scores, suggesting that age interactions with lifestyle measures may be missed if we only examine typically declining measures.

\section{Limitations and benefits of the Cam-CAN dataset for diverse cognitive assessment}

The current study points to the need to develop more multidimensional, lifespan models of cognitive aging, to explore the specific relationships between lifestyle measures and cognition across the lifespan, and to develop better methods for characterizing cognitive diversity. The present results are limited in their ability to achieve these goals, both by the reported analyses (which use a fairly exploratory approach), and by limitations of the Cam-CAN dataset itself. First, while Cam-CAN recruitment was population-based, it was not population-representative, and participants who completed full cognitive assessments were qualified to undergo cognitive neuroscience experiments including neuroimaging (see Shafto et al., 2014 for a description of participant selection for testing stages). As detailed in the Methods, Green et al. (2018) suggest that both age and deprivation may affect initial participation rates in Stage 1, although characteristics of participants who dropped out during Stage 2 have not yet been fully assessed.

Second, the Cam-CAN cohort is cross-sectional, with the attendant limitations on our ability to draw causal conclusions about the relationships between age, cognition and lifestyle measures. Models of cognitive aging based on cognitive-behavioural experiments have relied heavily on cross-sectional data, resulting in an ongoing debate about the validity of longitudinal compared to cross-sectional evidence. Proponents of longitudinal approaches argue that cross-sectional data over-estimates differences in performance across the age range (Nilsson, Sternäng, Rönnlund, \& Nyberg, 2009; Rönnlund, Nyberg, Bäckman, \& Nilsson, 2005; Salthouse, 2009; Singh-Manoux et al., 2012) while proponents of cross- 


\section{HEALTHY COGNITIVE AGING}

sectional studies argue that longitudinal use of targeted cognitive experiments is vulnerable to substantial practice effects (Salthouse, 2010a). In the current findings, cross-sectional measurement may particularly impact our understanding of the role of educational attainment, as cohort differences in education have been put forward as explaining the differences between cross-sectional and longitudinal findings (Rönnlund et al., 2005; Singh-Manoux et al., 2012). We cannot know what impact cohort differences in education had on the current results, but education did not merely serve as a proxy for age, as education had a variety of relationships to different cognitive factors across the age range. For example, increased education was strongly related to Crystallized Abilities, a cognitive measure which itself improved with age (while educational attainment declined); this finding highlights he complex role of education, not only as a proxy for cohort effects, but as an important reflection of cognitive reserve.

While the Cam-CAN dataset has limitations due to being cross-sectional, it serves as a complement to longitudinal datasets by providing features that are difficult to achieve longitudinally. First, while longitudinal studies of cognitive aging with younger or middle-aged participants are not unheard of (Singh-Manoux et al., 2012), practicalities mean studies more typically examine older people only (e.g., French, Sargent-Cox, \& Luszcz, 2012; Lee, Chi, \& Palinkas, 2018). Second, the range of measures available in the Cam-CAN dataset would be difficult to acquire longitudinally. As previously noted, experimental cognitive data can be very vulnerable to practice effects, even with long delays between tests. Moreover, participants attended up to seven testing sessions to provide the range of cognitive and lifestyle measures reported here as well as the wealth of health, wellness, multi-model neuroimaging and cognitive neuroscience data available in the full dataset. This breadth of testing would be unrealistic in a longitudinal study.

A final limitation of the current study is that, while the Cam-CAN dataset uses an unusually diverse range of cognitive experiments, the factors that emerge from a PCA or related approach will depend on 


\section{HEALTHY COGNITIVE AGING}

the variables included, and no single dataset can be all-inclusive. Moreover, the current study used PCA as part of an exploratory approach, to provide a summary of the data, so we do not provide a more focused test of underlying factor structure (e.g., see Borgeest et al., 2018). Despite the limitations of any one dataset, a picture of diverse cognitive aging can be developed if future cohort studies include more (1) domain-specific measures that are likely to reflect normal rather than pathological individual differences, and (2) measures that have differential relationships to age rather than focusing on declines. Importantly, cohorts with diverse cognitive assessment such as in the Cam-CAN dataset are also able to contribute to the understanding of domain-general function and cognitive factors that may be related to pathology in later life, as is evident from the domain-general Fluid Abilities and Typically Declining factors. Indeed, this type of dataset is amenable to identifying the effect of lifestyle choices on broad cognitive abilities that are common across the lifespan (Borgeest et al., 2018).

\section{Conclusions}

Developing models of successful cognitive aging should not be driven by a focus on declines in cognitive health in late life, but should also include an examination of the whole adult lifespan and domain-specific processes that may be stable or improve with age. The Cam-CAN dataset provides an important resource that supports the growing vision of cognitive aging as a life-long developmental process with complex relationships across life stages and cognitive domains. 


\section{References}

Ang, S. (2018). Social participation and health over the adult life course: Does the association strengthen with age? Social Science \& Medicine, 206, 51-59. https://doi.org/10.1016/J.SOCSCIMED.2018.03.042

Baddeley, A., Emslie, H., \& Nimmo-Smith, I. (1993). The Spot-the-Word test: A robust estimate of verbal intelligence based on lexical decision. The British Journal of Clinical Psychology / the British Psychological Society, 32 ( Pt 1), 55-65. https://doi.org/dx.doi.org/10.1111/j.20448260.1993.tb01027.x

Bielak, A. A. M., Gerstorf, D., Anstey, K. J., \& Luszcz, M. A. (2014). Longitudinal associations between activity and cognition vary by age, activity type, and cognitive domain. Psychology and Aging, 29(4), 863-872. https://doi.org/10.1037/a0036960

Borgeest, G. S., Henson, R., Shafto, M., Samu, D., \& Kievit, R. (2018). Greater lifestyle engagement is associated with healthy cognitive ageing. https://doi.org/10.31234/osf.io/6pzve

Bourassa, K. J., Memel, M., Woolverton, C., \& Sbarra, D. A. (2017). Social participation predicts cognitive functioning in aging adults over time: Comparisons with physical health, depression, and physical activity. Aging \& Mental Health, 21(2), 133-146.

https://doi.org/10.1080/13607863.2015.1081152

Burke, D. M., MacKay, D. G., Worthley, J. S., \& Wade, E. (1991). On the tip-of-the-tongue: What causes word finding failures in young and older adults? Journal of Memory and Language, 30 , 542-579. https://doi.org/doi:10.1016/0749-596X(91)90026-G

Burke, D. M., \& Shafto, M. A. (2008). Language and aging. In F. I. M. Craik \& T. A. Salthouse (Eds.), 


\section{HEALTHY COGNITIVE AGING}

The Handbook of Aging and Cognition (pp. 373-443). New York \& Hove: Psychology Press.

Chan, D., Shafto, M., Kievit, R., Matthews, F., Spink, M., Valenzuela, M., ... Henson, R. N. (2018). Lifestyle activities in mid-life contribute to cognitive reserve in late-life, independent of education, occupation, and late-life activities. Neurobiology of Aging, 70, 180-183. https://doi.org/10.1016/j.neurobiolaging.2018.06.012

Chapko, D., McCormack, R., Black, C., Staff, R., \& Murray, A. (2017). Life-course determinants of cognitive reserve (CR) in cognitive aging and dementia - a systematic literature review. Aging \& Mental Health, 1-12. https://doi.org/10.1080/13607863.2017.1348471

Clare, L., Wu, Y.-T., Teale, J. C., MacLeod, C., Matthews, F., Brayne, C., ... CFAS-Wales study team, C.-W. study. (2017). Potentially modifiable lifestyle factors, cognitive reserve, and cognitive function in later life: A cross-sectional study, 14(3), e1002259. https://doi.org/10.1371/journal.pmed.1002259

Costello, A. B., \& Osborne, J. W. (2005). Best practices in exploratory factor analysis: Four recommendations for getting the most from your analysis. Practical Assessment, Research and Evaluation, 10(7). Retrieved from http://www.statsoft.com/textbook/stathome.html.

Daffner, K. R. (2010). Promoting Successful Cognitive Aging: A Comprehensive Review. Journal of Alzheimer's Disease, 19(4), 1101-1122. https://doi.org/10.3233/JAD-2010-1306

de Mooij, S. M. M., Henson, R. N. A., Waldorp, L. J., Kievit, R. A., \& Kievit, R. A. (2018). Age Differentiation within Gray Matter, White Matter, and between Memory and White Matter in an Adult Life Span Cohort. The Journal of Neuroscience: The Official Journal of the Society for Neuroscience, 38(25), 5826-5836. https://doi.org/10.1523/JNEUROSCI.1627-17.2018 


\section{HEALTHY COGNITIVE AGING}

Deary, I. J., Gow, A. J., Pattie, A., \& Starr, J. M. (2012). Cohort Profile: The Lothian Birth Cohorts of 1921 and 1936. International Journal of Epidemiology, 41(6), 1576-1584. https://doi.org/10.1093/ije/dyr197

Depp, C. A., Harmell, A., \& Vahia, I. V. (2011). Successful Cognitive Aging (pp. 35-50). Springer, Berlin, Heidelberg. https://doi.org/10.1007/7854_2011_158

Folstein, M. F., Folstein, S. E., \& McHugh, P. R. (1975). "Mini-mental state" a practical method for grading the cognitive state of patients for the clinician. Journal of Psychiatric Research, 12, 189198. https://doi.org/10.1016/0022-3956(75)90026-6

French, D. J., Sargent-Cox, K., \& Luszcz, M. A. (2012). Correlates of Subjective Health Across the Aging Lifespan. Journal of Aging and Health, 24(8), 1449-1469. https://doi.org/10.1177/0898264312461151

Ganguli, M., Snitz, B. E., Lee, C.-W., Vanderbilt, J., Saxton, J. A., \& Chang, C.-C. H. (2010). Age and education effects and norms on a cognitive test battery from a population-based cohort: The Monongahela-Youghiogheny Healthy Aging Team. Aging \& Mental Health, 14(1), 100-107. https://doi.org/10.1080/13607860903071014

Gerstorf, D., Ram, N., Hoppmann, C., Willis, S. L., \& Schaie, K. W. (2011). Cohort differences in cognitive aging and terminal decline in the Seattle Longitudinal Study. Developmental Psychology, 47(4), 1026-1041. https://doi.org/10.1037/a0023426

Green, E., Bennett, H., Brayne, C., Tyler, L. K., Bullmore, E. T., Calder, A. C., ... Matthews, F. E. (2018). Exploring patterns of response across the lifespan: The Cambridge Centre for Ageing and Neuroscience (Cam-CAN) study. BMC Public Health, 18(1). https://doi.org/10.1186/s12889-018$5663-7$ 


\section{HEALTHY COGNITIVE AGING}

Hartley, A., Angel, L., Castel, A., Didierjean, A., Geraci, L., Hartley, J., ... Touron, D. (2018).

Successful aging: The role of cognitive gerontology. Experimental Aging Research, 44(1), 82-93. https://doi.org/10.1080/0361073X.2017.1398849

Hultsch, D. F., MacDonald, S. W. S., \& Dixon, R. A. (2002). Variability in Reaction Time Performance of Younger and Older Adults. The Journals of Gerontology Series B: Psychological Sciences and Social Sciences, 57(2), P101-P115. https://doi.org/10.1093/geronb/57.2.P101

Hülür, G., Ram, N., Willis, S. L., Schaie, K. W., \& Gerstorf, D. (2015). Cognitive dedifferentiation with increasing age and proximity of death: Within-person evidence from the Seattle Longitudinal Study. Psychology and Aging, 30(2), 311-323. https://doi.org/10.1037/a0039260

James, B. D., Wilson, R. S., Barnes, L. L., \& Bennett, D. A. (2011). Late-Life Social Activity and Cognitive Decline in Old Age. Journal of the International Neuropsychological Society, 17(06), 998-1005. https://doi.org/10.1017/S1355617711000531

James, L. E., \& Burke, D. M. (2000). Phonological priming effects on word retrieval and tip-of-thetongue experiences. Journal of Experimental Psychology: Learning, Memory, and Cognition, 26, 1378-1391. https://doi.org/10.1037/0278-7393.26.6.1378

Jonaitis, E., La Rue, A., Mueller, K., Koscik, R., Hermann, B., \& Sager, M. A. (2013). Cognitive activities and cognitive performance in middle-aged adults at risk for Alzheimer's disease. Psychology and Aging, 28(4), 1004-1014.

Kobayashi, L. C., Wardle, J., Wolf, M. S., \& von Wagner, C. (2015). Cognitive Function and Health Literacy Decline in a Cohort of Aging English Adults. Journal of General Internal Medicine, 30(7), 958-964. https://doi.org/10.1007/s11606-015-3206-9 


\section{HEALTHY COGNITIVE AGING}

Lee, Y., Chi, I., \& Palinkas, L. A. (2018). Retirement, Leisure Activity Engagement, and Cognition Among Older Adults in the United States. Journal of Aging and Health, 089826431876703. https://doi.org/10.1177/0898264318767030

Li, S.-C., Schmiedek, F., Huxhold, O., Röcke, C., Smith, J., \& Lindenberger, U. (2008). Working memory plasticity in old age: Practice gain, transfer, and maintenance. Psychology and Aging, 23(4), 731-742. https://doi.org/10.1037/a0014343

Lindenberger, U., \& Baltes, P. B. (1997). Intellectual functioning in old and very old age: CrossSectional results from the Berlin Aging Study. Psychology and Aging, 12(3), 410-432. https://doi.org/10.1037/0882-7974.12.3.410

Lindenberger, U., \& Ghisletta, P. (2009). Cognitive and sensory declines in old age: Gauging the evidence for a common cause. Psychology and Aging, 24(1), 1-16. https://doi.org/10.1037/a0014986

Marioni, R. E., Proust-Lima, C., Amieva, H., Brayne, C., Matthews, F. E., Dartigues, J.-F., \& JacqminGadda, H. (2014). Cognitive lifestyle jointly predicts longitudinal cognitive decline and mortality risk. European Journal of Epidemiology, 29(3), 211-219. https://doi.org/10.1007/s10654-014$9881-8$

Marioni, R. E., van den Hout, A., Valenzuela, M. J., Brayne, C., Matthews, F. E., \& Study, M. C. F. and A. (2012). Active Cognitive Lifestyle Associates with Cognitive Recovery and a Reduced Risk of Cognitive Decline. Journal of Alzheimer's Disease, 28(1), 223-230. https://doi.org/10.3233/JAD2011-110377

Matthews, F., Marioni, R., \& Brayne, C. (2012). Examining the influence of gender, education, social class and birth cohort on MMSE tracking over time: A population-based prospective cohort study. 


\section{HEALTHY COGNITIVE AGING}

BMC Geriatrics, 12(1), 45. https://doi.org/10.1186/1471-2318-12-45

Meng, X., \& D'Arcy, C. (2012). Education and Dementia in the Context of the Cognitive Reserve Hypothesis: A Systematic Review with Meta-Analyses and Qualitative Analyses. PLoS ONE, 7(6), e38268. https://doi.org/10.1371/journal.pone.0038268

Miller, L. S., Mitchell, M. B., Woodard, J. L., Davey, A., Martin, P., Poon, L. W., \& Georgia Centenarian Study. (2010). Cognitive Performance in Centenarians and the Oldest Old: Norms from the Georgia Centenarian Study. Aging, Neuropsychology, and Cognition, 17(5), 575-590. https://doi.org/10.1080/13825585.2010.481355

Nilsson, L.-G., Sternäng, O., Rönnlund, M., \& Nyberg, L. (2009). Challenging the notion of an earlyonset of cognitive decline. Neurobiology of Aging, 30(4), 521-524. https://doi.org/10.1016/J.NEUROBIOLAGING.2008.11.013

Opdebeeck, C., Martyr, A., \& Clare, L. (2016). Cognitive reserve and cognitive function in healthy older people: a meta-analysis. Aging, Neuropsychology, and Cognition, 23(1), 40-60. https://doi.org/10.1080/13825585.2015.1041450

Park, D. C., Lautenschlager, G., Hedden, T., Davidson, N. S., Smith, A. D., \& Smith, P. K. (2002). Models of visuospatial and verbal memory across the adult life span. Psychology and Aging, 17(2), 299-320. https://doi.org/http://dx.doi.org/10.1037/0882-7974.17.2.299

Rönnlund, M., Nyberg, L., Bäckman, L., \& Nilsson, L.-G. (2005). Stability, growth, and decline in adult life span development of declarative memory: cross-sectional and longitudinal data from a population-based study. Psychology and Aging, 20(1), 3-18. https://doi.org/10.1037/08827974.20.1.3 


\section{HEALTHY COGNITIVE AGING}

Saint Martin, M., Sforza, E., Barthélémy, J. C., Roche, F., Lefèvre, P., Liénard, G., \& Thomas-Anterion, C. (2017). Long-lasting active lifestyle and successful cognitive aging in a healthy elderly population: The PROOF cohort. Revue Neurologique, 173(10), 637-644. https://doi.org/10.1016/J.NEUROL.2017.05.009

Salthouse, T. A. (2009). When does age-related cognitive decline begin? Neurobiology of Aging, 30(4), 507-514. https://doi.org/10.1016/j.neurobiolaging.2008.09.023

Salthouse, T. A. (2010a). Influence of age on practice effects in longitudinal neurocognitive change. Neuropsychology, 24(5), 563-572. https://doi.org/10.1037/a0019026

Salthouse, T. A. (2010b). Selective review of cognitive aging. Journal of the International Neuropsychological Society : JINS, 16(5), 754-760. https://doi.org/10.1017/S1355617710000706

Salthouse, T. A., \& Ferrer-Caja, E. (2003). What needs to be explained to account for age-related effects on multiple cognitive variables? Psychology and Aging, 18(1), 91-110. https://doi.org/10.1037/0882-7974.18.1.91

Schweizer, S., Stretton, J., Van Belle, J., Price, D., Calder, A. J., \& Dalgleish, T. (2019). Age-related decline in positive emotional reactivity and emotion regulation in a population-derived cohort. Social Cognitive and Affective Neuroscience. https://doi.org/10.1093/scan/nsz036

Seeman, T. E., Miller-Martinez, D. M., Stein Merkin, S., Lachman, M. E., Tun, P. A., \& Karlamangla, A. S. (2011). Histories of Social Engagement and Adult Cognition: Midlife in the U.S. Study. The Journals of Gerontology Series B: Psychological Sciences and Social Sciences, 66B(Supplement 1), i141-i152. https://doi.org/10.1093/geronb/gbq091

Shafto, M. A., Burke, D. M., Stamatakis, E. A., Tam, P. P., \& Tyler, L. K. (2007). On the tip-of-the- 


\section{HEALTHY COGNITIVE AGING}

tongue: Neural correlates of increased word-finding failures in normal aging. Journal of Cognitive Neuroscience, 19(12), 2060-2070. https://doi.org/10.1162/jocn.2007.19.12.2060

Shafto, M. A., \& Tyler, L. K. (2014). Language in the aging brain: The network dynamics of cognitive decline and preservation. Science, 346(6209), 583-587. https://doi.org/10.1126/science.1254404

Shafto, M. A., Tyler, L. K., Dixon, M., Taylor, J. R., Rowe, J. B., Cusack, R., ... Matthews, F. E. (2014). The Cambridge Centre for Ageing and Neuroscience (Cam-CAN) study protocol: A crosssectional, lifespan, multidisciplinary examination of healthy cognitive ageing. BMC Neurology, 14(204), 204. https://doi.org/10.1186/s12883-014-0204-1

Singh-Manoux, A., Kivimaki, M., Glymour, M. M., Elbaz, A., Berr, C., Ebmeier, K. P., ... Dugravot, A. (2012). Timing of onset of cognitive decline: results from Whitehall II prospective cohort study. BMJ, 344(jan04 4), d7622-d7622. https://doi.org/10.1136/bmj.d7622

Snellen, H. (1862). Probebuchstaben zur Bestimmung der Sehschärfe. Utrecht: Van de Weijer.

Taylor, J. K., \& Burke, D. M. (2002). Asymmetric aging effects on semantic and phonological processes: Naming in the picture-word interference task. Psychology and Aging, 17(4), 662-676. https://doi.org/http://dx.doi.org/10.1037/0882-7974.17.4.662

Taylor, J. R., Williams, N., Cusack, R., Auer, T., Shafto, M. A., Dixon, M., ... Henson, R. N. (2017). The Cambridge Centre for Ageing and Neuroscience (Cam-CAN) data repository: Structural and functional MRI, MEG, and cognitive data from a cross-sectional adult lifespan sample. NeuroImage, 144, 262-269. https://doi.org/10.1016/j.neuroimage.2015.09.018

Thornton, R., \& Light, L. L. (2006). Language comprehension and production in normal aging. In J. E. Birren \& K. W. Schaie (Eds.), Handbook of the Psychology of Aging. San Diego, CA: Elsevier. 


\section{HEALTHY COGNITIVE AGING}

https://doi.org/http://dx.doi.org/10.1016/B978-012101264-9/50015-X

Tyler, L. K., Shafto, M. A., Randall, B., Wright, P., Marslen-Wilson, W. D., \& Stamatakis, E. A. (2010).

Preserving syntactic processing across the adult life span: The modulation of the frontotemporal language system in the context of age-related atrophy. Cerebral Cortex, 20(2), 352-364. https://doi.org/10.1093/cercor/bhp105

Valenzuela, M., Brayne, C., Sachdev, P., \& Wilcock, G. (2011). Cognitive Lifestyle and Long-Term Risk of Dementia and Survival After Diagnosis in a Multicenter Population-based Cohort. American Journal of Epidemiology, 173(9), 1004-1012. https://doi.org/10.1093/aje/kwq476

Valenzuela, M. J., Matthews, F. E., Brayne, C., Ince, P., Halliday, G., Kril, J. J., ... Sachdev, P. S. (2012). Multiple Biological Pathways Link Cognitive Lifestyle to Protection from Dementia. Biological Psychiatry, 71(9), 783-791. https://doi.org/10.1016/J.BIOPSYCH.2011.07.036

Valenzuela, M. J., \& Sachdev, P. (2006, October 6). Brain reserve and dementia: A systematic review. Psychological Medicine. Cambridge University Press. https://doi.org/10.1017/S0033291705006264

Valenzuela, M. J., \& Sachdev, P. (2007). Assessment of complex mental activity across the lifespan: development of the Lifetime of Experiences Questionnaire (LEQ). Psychological Medicine, 37(7), 1015-1025. https://doi.org/10.1017/S003329170600938X

Verhaeghen, P. (2003). Aging and vocabulary score: A meta-analysis. Psychology and Aging, 18, 332339. https://doi.org/10.1037/0882-7974.18.2.332

Weschler, C. J. (1999). Wechsler Memory Scale. Third UK edition . London: Harcourt Assessment.

Wilson, R. S., Beckett, L. A., Barnes, L. L., Schneider, J. A., Bach, J., Evans, D. A., \& Bennett, D. A. (2002). Individual differences in rates of change in cognitive abilities of older persons. Psychology 


\section{HEALTHY COGNITIVE AGING}

and Aging, 17(2), 179-193. https://doi.org/10.1037/0882-7974.17.2.179 
HEALTHY COGNITIVE AGING

Table 1. Participant sample sizes, gender distribution, and highest educational attainment by sampling decile.

\begin{tabular}{|c|c|c|c|c|c|c|c|c|c|}
\hline & & \multicolumn{8}{|c|}{ Decile } \\
\hline & & $18-27$ & $28-37$ & $38-47$ & $48-57$ & $58-67$ & $68-77$ & $78-88$ & Total \\
\hline Sample size & & 56 & 108 & 114 & 103 & 109 & 110 & 108 & 708 \\
\hline $\begin{array}{l}\text { Gender } \\
\text { (Percent Female per deci }\end{array}$ & & 52 & 52 & 50 & 52 & 50 & 53 & 47 & 51 \\
\hline \multirow[t]{4}{*}{$\begin{array}{l}\text { Education } \\
\text { (\% of total by category) }\end{array}$} & $\begin{array}{l}\text { No qualifications } \\
\text { tried } \\
\text { (under 16) }\end{array}$ & $<1$ & 1 & $<1$ & 5 & 5 & 17 & 15 & 7 \\
\hline & GCSE (age 16) & 21 & 6 & 12 & 12 & 16 & 18 & 14 & 14 \\
\hline & A-levels (age 18) & 21 & 12 & 13 & 21 & 21 & 22 & 27 & 20 \\
\hline & University (over 18) & 57 & 81 & 75 & 62 & 58 & 43 & 44 & 60 \\
\hline
\end{tabular}


HEALTHY COGNITIVE AGING

Table 2. Results of regressing individual cognitive measures on Age (Model 1) and both Age and Age ${ }^{2}$ (Model 2). Standardized $\beta$ values for expressions of age are reported, as well as explained variance $\left(R^{2}\right)$, change in explained variance $\left(\Delta R^{2}\right.$, Model 2$)$, effect sizes $\left(C o h e n F^{2}\right)$ and $F$ (Model 1) and $\Delta F$ (Model 2) values. The values of measures used in the regression models were aligned so that higher values represent better performance.

\begin{tabular}{|c|c|c|c|c|c|c|c|c|c|c|c|}
\hline Domain & Measures & Model 1 & & & & Model 2 & & & & & \\
\hline & & Age & $\mathbf{R}^{2}$ & $\begin{array}{l}\text { Cohen } \\
\text { F }^{2}\end{array}$ & $\mathbf{F}$ & Age & Age $^{2}$ & $\mathbf{R}^{2}$ & $\begin{array}{l}\text { Cohen } \\
\text { F }^{2}\end{array}$ & $\Delta \mathbf{R}^{2}$ & $\Delta \mathbf{F}$ \\
\hline \multirow[t]{4}{*}{ Attention/Executive } & Fluid Intelligence & $-.66 * *$ & .44 & 0.79 & $508.20 * *$ & .29 & $-.96 * *$ & .46 & 0.85 & .02 & $27.83 * *$ \\
\hline & Multitasking & $-.26 * *$ & .07 & 0.08 & $46.54 * *$ & .36 & $-.63 * *$ & .08 & 0.09 & .01 & $6.89 * *$ \\
\hline & Verbal Fluency & $-.29 *$ & .08 & 0.09 & $64.97 * *$ & $.95 * *$ & $-1.25 * *$ & .12 & 0.14 & .04 & $31.48 * *$ \\
\hline & Choice RT & $-.63 * *$ & .40 & 0.67 & $436.89 * *$ & -.27 & -.37 & .40 & 0.67 & .003 & 3.82 \\
\hline \multirow[t]{3}{*}{ Language } & Picture Naming & $-.51 * *$ & .26 & 0.35 & $200.16 * *$ & $1.35 * *$ & $-1.88 * *$ & .34 & 0.52 & .09 & $77.43 * *$ \\
\hline & TOTs & $-.31 * *$ & .10 & 0.11 & $70.39 * *$ & $.78 * *$ & $-1.11 * *$ & .13 & 0.15 & .03 & $21.72 * *$ \\
\hline & $\begin{array}{l}\text { Sentence } \\
\text { Comprehension }\end{array}$ & .02 & $<.01$ & $<.01$ & 0.22 & -.11 & .13 & $<.01$ & $<.01$ & $<.01$ & .26 \\
\hline \multirow[t]{2}{*}{ Emotion Processing } & Emotion Recognition & $-.43 * *$ & .19 & 0.23 & $151.29 * *$ & $.66 * *$ & $-1.11 * *$ & .22 & 0.28 & .03 & $25.24 * *$ \\
\hline & Emotion Reactivity & $-.30 * *$ & .09 & 0.10 & $27.71 * *$ & .66 & $-.97 * *$ & .11 & 0.12 & .03 & $7.92 * *$ \\
\hline
\end{tabular}


HEALTHY COGNITIVE AGING

\begin{tabular}{|c|c|c|c|c|c|c|c|c|c|c|c|}
\hline & Emotion Reappraisal & .01 & $<.01$ & $<.01$ & .01 & -.28 & .29 & $<.01$ & $<.01$ & $<.01$ & .64 \\
\hline \multirow[t]{5}{*}{ Memory } & VSTM Capacity & $-.43 * *$ & .18 & 0.22 & $146.06 * *$ & $.70 * *$ & $-1.15^{* *}$ & .21 & 0.28 & .03 & $26.97 * *$ \\
\hline & Story Memory & $-.37 * *$ & .14 & 0.16 & $110.99 * *$ & .36 & $-.74 * *$ & .15 & 0.18 & .01 & $11.30 * *$ \\
\hline & Priming & $-.22 * *$ & .05 & 0.05 & $16.45 * *$ & -.11 & -.12 & .05 & 0.05 & $<.01$ & .11 \\
\hline & Recall & $-.57 * *$ & .32 & 0.47 & $154.90 * *$ & .04 & $-.62 *$ & .33 & 0.49 & .01 & $4.35^{*}$ \\
\hline & Recognition & $-.66 * *$ & .43 & 0.75 & $246.31 * *$ & -.22 & -.44 & .44 & 0.79 & .01 & 2.66 \\
\hline \multirow[t]{5}{*}{ Motor/Speed } & Balance Test & $-.58 * *$ & .33 & 0.49 & $331.06 * *$ & $-.60 * *$ & .03 & .33 & 0.49 & $<.01$ & .02 \\
\hline & Chair Rises & $-.35 * *$ & .12 & 0.14 & $95.19 * *$ & .30 & $-.65 * *$ & .13 & 0.15 & .01 & $8.58 * *$ \\
\hline & Simple RT & $-.35 * *$ & .12 & 0.14 & $92.35 * *$ & .15 & $-.51 *$ & .13 & 0.15 & .01 & $5.04 *$ \\
\hline & Force Matching & -.08 & .01 & 0.01 & 1.85 & .51 & -.60 & .02 & 0.02 & .01 & 2.96 \\
\hline & Motor Learning & $-.24 * *$ & .06 & 0.06 & $18.76^{* *}$ & .21 & -.45 & .06 & 0.06 & .01 & 1.73 \\
\hline \multirow[t]{2}{*}{ Face Processing } & Unfamiliar Faces & $-.46 * *$ & .21 & 0.27 & $175.49 * *$ & $.64 * *$ & $-1.11 * *$ & .24 & 0.32 & .03 & $26.27 * *$ \\
\hline & Familiar Faces & $-.33 * *$ & .11 & 0.12 & $78.00 * *$ & $2.19 * *$ & $-2.55 * *$ & .26 & 0.37 & .16 & $143.44 * *$ \\
\hline \multirow{3}{*}{$\begin{array}{l}\text { Crystallized } \\
\text { Knowledge }\end{array}$} & Spot the Word & $.22 * *$ & .05 & 0.05 & $36.50 * *$ & $.91 * *$ & $-.69 * *$ & .06 & 0.06 & .01 & $9.04 * *$ \\
\hline & & & & & & & & & & & \\
\hline & Proverbs & $.13 * *$ & .02 & 0.02 & $11.65 * *$ & $.98 * *$ & $-.86 * *$ & .03 & 0.04 & .02 & $12.47 * *$ \\
\hline
\end{tabular}

$* p<.05 ; * * p<.01$ 


\section{HEALTHY COGNITIVE AGING}

Table 3. Results of regressing Cross-domain and Typically Declining factor scores on Age (Model 1) and both Age and Age ${ }^{2}$ (Model 2).

Standardized $\beta$ values for expressions of age are reported, as well as explained variance $\left(R^{2}\right)$, change in explained variance $\left(\Delta R^{2}, M o d e l\right.$, and $F$ (Model 1) and $\Delta F$ (Model 2) values.

\begin{tabular}{|c|c|c|c|c|c|c|c|c|}
\hline \multirow[t]{2}{*}{ Factor } & \multicolumn{3}{|c|}{ Model 1} & \multicolumn{5}{|c|}{ Model 2} \\
\hline & Age & $\mathbf{R}^{2}$ & $\mathbf{F}$ & Age & Age $^{2}$ & $\mathbf{R}^{2}$ & $\Delta \mathbf{R}^{2}$ & $\Delta \mathbf{F}$ \\
\hline $\begin{array}{l}\text { Factor 1: } \\
\text { Fluid Abilities }\end{array}$ & $-.70 * *$ & .49 & $416.02 * *$ & $-.61 * *$ & -.09 & .49 & $<.01$ & .16 \\
\hline $\begin{array}{l}\text { Factor } 2 \text { : } \\
\text { Naming }\end{array}$ & $-.35 * *$ & .12 & $60.77 * *$ & $2.04 * *$ & $-2.42 * *$ & .27 & .14 & $84.75 * *$ \\
\hline $\begin{array}{l}\text { Factor3: } \\
\text { Crystallized Abilities }\end{array}$ & $.18^{* *}$ & .03 & $14.16^{* *}$ & .52 & -.34 & .04 & $<.01$ & 1.30 \\
\hline $\begin{array}{l}\text { Factor 4: } \\
\text { Sentence Comprehension }\end{array}$ & .05 & $<.01$ & 1.13 & .20 & -.15 & $<.01$ & $<.01$ & .23 \\
\hline Typically Declining Factor & $-.68 * *$ & .46 & $489.96 * *$ & $.42 *$ & $-1.11 * *$ & .49 & .03 & $34.22 * *$ \\
\hline
\end{tabular}

$* p<.05 ; * * p<.01$ 
Table 4. Results of regressing Cross-domain and Typically Declining factor scores on lifestyle measures with age and gender covariates. Standardized $\beta$ values are reported, as well as explained variance $\left(R^{2}\right)$ and $F$ values for each model.

\begin{tabular}{|c|c|c|c|c|c|c|c|c|c|c|}
\hline & Gender & Age & Education & $\begin{array}{c}\text { Social } \\
\text { engagement }\end{array}$ & $\begin{array}{c}\text { Enrichment } \\
\text { activities }\end{array}$ & $\begin{array}{c}\text { Age } x \\
\text { Education }\end{array}$ & $\begin{array}{c}\text { Age } x \\
\text { Social } \\
\text { engagement }\end{array}$ & $\begin{array}{c}\text { Age } x \\
\text { Enrichment } \\
\text { activities }\end{array}$ & $\mathbf{R}^{2}$ & $\mathbf{F}$ \\
\hline $\begin{array}{l}\text { Factor 1: } \\
\text { Fluid Abilities }\end{array}$ & .01 & $-.63 * *$ & $.16^{* * *}$ & -.05 & $.11 * *$ & $<.01$ & $.08^{*}$ & -.03 & .58 & $56.54 * *$ \\
\hline $\begin{array}{l}\text { Factor 2: } \\
\text { Naming }\end{array}$ & .07 & $-.39 * *$ & .08 & .04 & -.07 & -.01 & $-.21 * *$ & $.11^{*}$ & .20 & $10.08 * *$ \\
\hline $\begin{array}{l}\text { Factor 3: } \\
\text { Crystallized } \\
\text { Abilities }\end{array}$ & .01 & $.38 * *$ & $.52 * *$ & $-.11 *$ & .08 & $.14 * *$ & $<.01$ & $-.10 *$ & .36 & $22.46^{* *}$ \\
\hline $\begin{array}{l}\text { Factor 4: } \\
\text { Sentence } \\
\text { Comprehension }\end{array}$ & $.20 * *$ & -.04 & -.11 & .02 & -.08 & .11 & .01 & .05 & .06 & $2.78^{\dagger}$ \\
\hline $\begin{array}{l}\text { Typically Declining } \\
\text { Factor }\end{array}$ & .03 & $-.61 * *$ & $.25 * *$ & -.01 & .07 & .01 & -.03 & -.02 & .57 & $70.45^{* *}$ \\
\hline
\end{tabular}

${ }^{*} p<.05 ;{ }^{\dagger} p<.05$, does not survive Bonferroni correction; $* * p<.01$ 
Figure 1. Cross-domain factor scores by sampling decile.

(A) Factor 1 Fluid Abilities

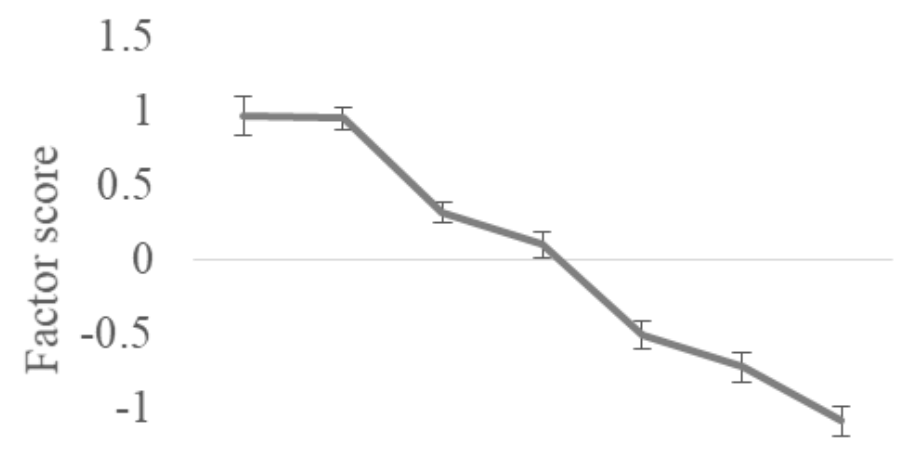

$-1.5$

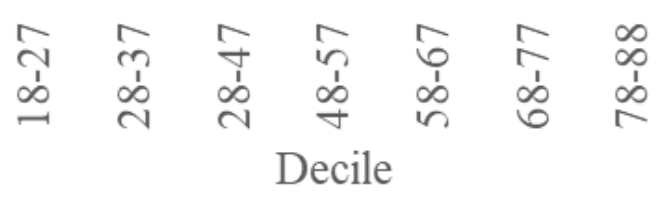

(C) Factor 3 Crystallized

Abilities

1
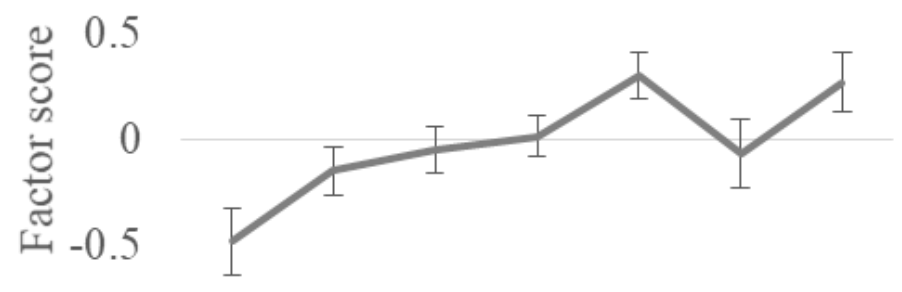

$-1$
(B) Factor 2 Naming

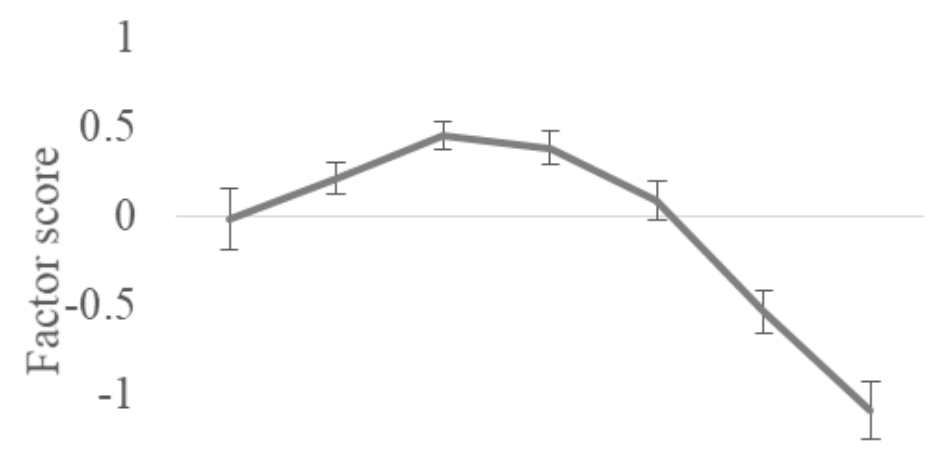

$-1.5$
(D) Factor 4 Sentence

1 Comprehension

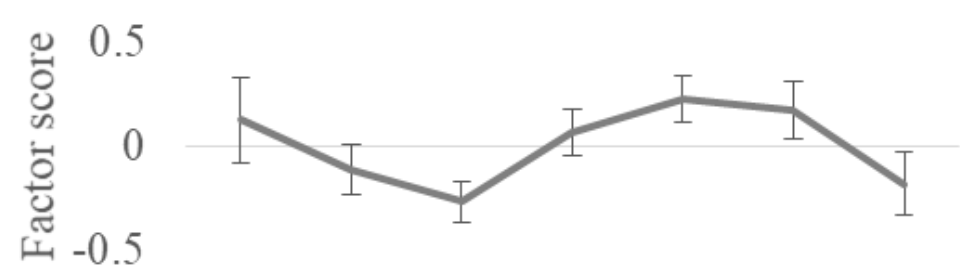

$-1$

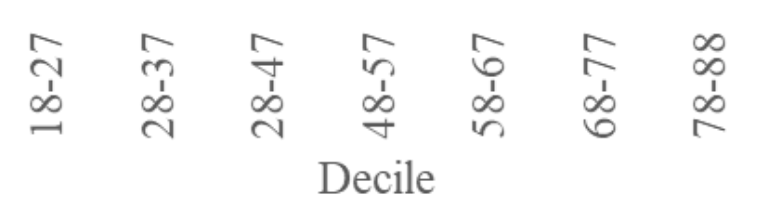


HEALTHY COGNITIVE AGING

\section{Online Supplement:}

Cognitive diversity in a healthy aging cohort: Cross-domain cognition in the Cam-CAN project

Supplemental Table 1. Cognitive tasks, variables, and measures across cognitive domains. Tasks are indicated whose measures are included in the Cross-domain PCA and Typically Declining PCA.

\begin{tabular}{|c|c|c|c|c|}
\hline Domain & Task & $\mathbf{N}$ & Variables & Cognitive Measures \\
\hline \multirow[t]{4}{*}{ Attention/Executive } & Fluid Intelligence & 660 & Total (out of 46) & Fluid Intelligence \\
\hline & Multitasking & 658 & $\begin{array}{l}\text { Time Deviation } \\
\text { Tasks Completed (out of 5) }\end{array}$ & Multitasking \\
\hline & Verbal Fluency & 706 & $\begin{array}{l}\text { Letter Fluency Total } \\
\text { Category Fluency Total }\end{array}$ & Verbal Fluency \\
\hline & Choice Response Time & 657 & $\begin{array}{l}\text { Mean RT } \\
\text { Covariance }\end{array}$ & Choice RT \\
\hline \multirow[t]{3}{*}{ Language } & Picture-picture priming & 648 & $\begin{array}{l}\text { Accuracy } \\
\text { Response Time } \\
\text { Phonological Priming } \\
\text { Semantic Priming }\end{array}$ & Picture Naming \\
\hline & Tip of the Tongue & 644 & TOT Rate & TOTs \\
\hline & Sentence comprehension & 627 & $\begin{array}{l}\text { Syntactic Processing } \\
\text { Semantic Processing }\end{array}$ & $\begin{array}{l}\text { Sentence } \\
\text { Comprehension }\end{array}$ \\
\hline Emotion processing & Emotion Recognition & 657 & Anger Correct Total & Emotion Recognition \\
\hline
\end{tabular}




\begin{tabular}{|c|c|c|c|c|}
\hline & & & $\begin{array}{l}\text { Disgust Correct Total } \\
\text { Fear Correct Total } \\
\text { Happiness Correct Total } \\
\text { Sadness Correct Total } \\
\text { Surprise Correct Total }\end{array}$ & \\
\hline & $\begin{array}{l}\text { Emotion Reactivity and } \\
\text { Regulation }\end{array}$ & 289 & $\begin{array}{l}\text { Positive Reactivity } \\
\text { Negative Reactivity } \\
\text { Positive Reappraisal } \\
\text { Negative Reappraisal }\end{array}$ & $\begin{array}{l}\text { Emotion Reactivity } \\
\text { Emotion Reappraisal }\end{array}$ \\
\hline \multirow[t]{3}{*}{ Memory } & $\begin{array}{l}\text { Visual Short Term Memory } \\
\text { (VSTM) }\end{array}$ & 656 & $\begin{array}{l}\text { Capacity Load } 1 \\
\text { Capacity Load } 2 \\
\text { Capacity Load } 3 \\
\text { Capacity Load } 4\end{array}$ & VSTM Capacity \\
\hline & Story Memory & 707 & $\begin{array}{l}\text { Recall Immediate } \\
\text { Recall Delayed } \\
\text { Recognition }\end{array}$ & Story Memory \\
\hline & Emotional Memory & 325 & $\begin{array}{l}\text { Priming Positive } \\
\text { Priming Neutral } \\
\text { Priming Negative } \\
\text { Recognition Positive } \\
\text { Recognition Neutral } \\
\text { Recognition Negative } \\
\text { Recall Positive }\end{array}$ & $\begin{array}{l}\text { Priming } \\
\text { Recognition } \\
\text { Recall }\end{array}$ \\
\hline
\end{tabular}




\begin{tabular}{|c|c|c|c|c|}
\hline & & & $\begin{array}{l}\text { Recall Neutral } \\
\text { Recall Negative }\end{array}$ & \\
\hline \multirow[t]{5}{*}{ Motor/Speed } & Foot Stands & 670 & $\begin{array}{l}\text { Seconds Balanced } \\
\text { (out of } 30 \text { ) }\end{array}$ & Balance Test \\
\hline & Chair Rises & 688 & Completion Time & Chair Rises \\
\hline & Simple Reaction Time & 658 & Response Time & Simple RT \\
\hline & Force matching & 322 & $\begin{array}{l}\text { Overcompensation Finger } \\
\text { Overcompensation Slider }\end{array}$ & Force Matching \\
\hline & Motor Learning & 318 & $\begin{array}{l}\text { Learning Rate Response Time } \\
\text { Learning Rate Error }\end{array}$ & Motor Learning \\
\hline \multirow[t]{2}{*}{ Face processing } & $\begin{array}{l}\text { Face Recognition: Unfamiliar } \\
\text { faces }\end{array}$ & 657 & Correct Total & Unfamiliar Faces \\
\hline & $\begin{array}{l}\text { Face Recognition: Familiar } \\
\text { faces }\end{array}$ & 659 & $\begin{array}{l}\text { Name Correct } \\
\text { Occupation Correct } \\
\text { Familiarity Correct }\end{array}$ & Familiar Faces \\
\hline \multirow[t]{2}{*}{$\begin{array}{l}\text { Crystallized } \\
\text { Knowledge }\end{array}$} & Spot the Word & 705 & $\begin{array}{l}\text { Correct Total } \\
\text { (out of } 60 \text { ) }\end{array}$ & Spot the Word \\
\hline & Proverbs & 655 & $\begin{array}{l}\text { Correct Total } \\
\text { (out of } 12 \text { ) }\end{array}$ & Proverbs \\
\hline
\end{tabular}


Supplemental Table 2. Cross-domain and Typically Declining PCA results, with factor loadings for each cognitive measure on four Cross-domain and one Typically Declining factor.

\begin{tabular}{|c|c|c|c|c|c|}
\hline & \multicolumn{4}{|c|}{ Cross-domain PCA } & \multirow{2}{*}{$\begin{array}{c}\text { Typically } \\
\text { Declining } \\
\text { PCA } \\
\text { Factor 1 }\end{array}$} \\
\hline & $\begin{array}{l}\text { Factor 1: } \\
\text { Fluid Abilities }\end{array}$ & $\begin{array}{l}\text { Factor 2: } \\
\text { Naming }\end{array}$ & $\begin{array}{c}\text { Factor 3: } \\
\text { Crystallized } \\
\text { Abilities }\end{array}$ & $\begin{array}{c}\text { Factor 4: } \\
\text { Sentence } \\
\text { Comprehension }\end{array}$ & \\
\hline Eigenvalue & 3.47 & 2.36 & 1.72 & 1.19 & 2.91 \\
\hline Percentage explained variance & 20.41 & 13.87 & 10.13 & 7.02 & 48.43 \\
\hline $\begin{array}{l}\text { Cum. Percentage explained } \\
\text { variance }\end{array}$ & 20.41 & 34.28 & 44.40 & 51.42 & 48.43 \\
\hline \multicolumn{6}{|c|}{ Loadings } \\
\hline Fluid Intelligence & 0.80 & 0.25 & 0.15 & 0.02 & 0.86 \\
\hline Choice RT & 0.75 & 0.13 & -0.04 & -0.07 & 0.75 \\
\hline
\end{tabular}


HEALTHY COGNITIVE AGING

\begin{tabular}{|c|c|c|c|c|c|}
\hline Balance Test & 0.61 & 0.12 & -0.07 & -0.38 & . \\
\hline VSTM Capacity & 0.58 & 0.26 & $<|.01|$ & 0.42 & 0.70 \\
\hline Story Memory & 0.56 & 0.14 & 0.33 & 0.11 & 0.65 \\
\hline Emotion Recognition & 0.53 & 0.35 & 0.25 & 0.16 & . \\
\hline Simple RT & $\mathbf{0 . 5 0}$ & 0.08 & -0.02 & -0.12 & 0.52 \\
\hline Verbal Fluency & $\mathbf{0 . 5 0}$ & 0.28 & 0.38 & 0.14 & 0.65 \\
\hline Chair Rises & 0.39 & 0.24 & -0.23 & -0.30 & . \\
\hline Familiar Faces & 0.04 & 0.86 & -0.12 & 0.13 & . \\
\hline TOTs & 0.12 & 0.63 & 0.29 & -0.01 & · \\
\hline Picture Naming & 0.40 & 0.62 & $<|.01|$ & -0.03 & . \\
\hline Unfamiliar Faces & 0.28 & 0.57 & -0.01 & -0.11 & - \\
\hline Multitasking & 0.25 & 0.27 & 0.13 & -0.14 & - \\
\hline Spot the Word & -0.01 & 0.05 & $\mathbf{0 . 8 0}$ & -0.12 & • \\
\hline Proverbs & 0.07 & $<|.01|$ & 0.75 & 0.02 & • \\
\hline Sentence Comprehension & -0.04 & -0.01 & -0.10 & 0.80 & . \\
\hline
\end{tabular}


HEALTHY COGNITIVE AGING

\section{Follow-up to Cross-domain PCA: Multi-group CFA}

Because the Cross-domain PCA factors were based on a wide age range (18-88 years), we used confirmatory factor analysis (CFA) to provide evidence that the components derived from this PCA were representative across age groups. Specifically, we developed a model based on the results of the Cross-domain PCA and tested the configural and measurement invariance across young, middle-aged and older age groups using multi-group CFA. Analyses were conducted in SPSS version 25 and AMOS version 26 (IBM, New York, USA). Data were included for all participants, and for CFA missing data was mean replaced. The model included three latent variables corresponding to the Fluid Abilities, Naming, and Crystallized Abilities factors with high loading measures as indicators (see Supplementary Table 2 for high loading measures). Because the Sentence Comprehension factor had only one high loading measure, in the place of a fourth latent variable we used the observed Sentence Comprehension measure. We tested configural invariance with a CFA including all 3 age groups, $\chi^{2}(342)=658.34, p<.001$. Fit indices suggested that while CFI did not indicate good fit, $(\mathrm{CFI}=.78)$ GFI was adequate (GFI= .91) and RMSEA and RMR were in good ranges (RMSEA = .036 with a 90\% CI [.032, .040], RMR=.056). As noted by Lai and Green (2016), it is not uncommon for fit indices to disagree, so model assessment benefits from using multiple indices. Additionally, although not all fit indices were in a good range, when the model was fit separately for each age group, fit indices were similar across groups for CFI (Young=.76, Middle-aged $=.79$, Older $=.78$ ), GFI $($ Young=.91, Middle-aged $=.90$, Older $=.91)$, RMR $($ Young $=.05$, Middle-aged $=.05$, Older $=$ .07 ), and RMSEA (Young=.065, Middle-aged $=.059$, Older $=.064$ ). Because the aim of the Cross-domain PCA was to summarize the data rather than test the dimensionality and structure of the dataset, the indices taken together suggest the model is a reasonable summary of the data 


\section{HEALTHY COGNITIVE AGING}

for all age groups. In order to test for invariance of the factor loadings across age groups, we used multi-group analysis to compare an unconstrained Model 1 to Model 2, which was constrained to make factor loadings equivalent across age groups. We first compared models across all three age groups, and using a chi-square test found evidence that the factor loadings were not invariant (See Supplementary Table 3; $\Delta \chi^{2}(26)=85.11, \mathrm{p}<.001$ ). To understand the source of this variance we repeated the multi-group analysis for just young and middle-aged groups, and for just middle-aged and older groups. These comparisons provided evidence for measurement invariance between middle-aged and older groups $\left(\Delta \chi^{2}(13)=21.06, p=.07\right)$ but a difference between young and middle-aged groups $\left(\Delta \chi^{2}(13)=31.02, p<.01\right)$. In order to identify the specific sources of variance between young and middle-aged groups we compared the unconstrained Model 1 to a series of models with individual factor loadings held constant across age groups. These results indicated stronger loadings in the middle-aged compared to younger adults for four parameters: one indicator of the Fluid Abilities factor (Emotion Recognition), $\left(\Delta \chi^{2}(1)=5.68, \mathrm{p}<.05\right)$, and three indicators of the Naming factor (TOTs, $\Delta \chi^{2}(1)=4.89, \mathrm{p}<.05$; Picture Naming, $\Delta \chi^{2}(1)=4.29, \mathrm{p}<.05$; and Unfamiliar Faces, $\left.\Delta \chi^{2}(1)=6.33, \mathrm{p}<.05\right)$.

Taken together, these analyses suggest that while a better fitting model could be possible, the components resulting from the Cross-domain PCA provide a reasonable summary of a wide range of cognitive measures across age groups. The measurement invariance analysis suggests some differences in factor loadings across the age-groups, which may provide focus for future research. In particular, the locus of variable factor loadings supports the importance of including a range of domain-specific cognitive measures and ages: the key age difference was between younger and middle-aged adults (rather than older adults) and involved stronger loadings for 


\section{HEALTHY COGNITIVE AGING}

parameters that were primarily relevant for the domain-specific Naming factor (rather than domain-general abilities). 


\section{HEALTHY COGNITIVE AGING}

Supplemental Table 3. Measurement invariance analysis using multi-group confirmatory factor analysis.

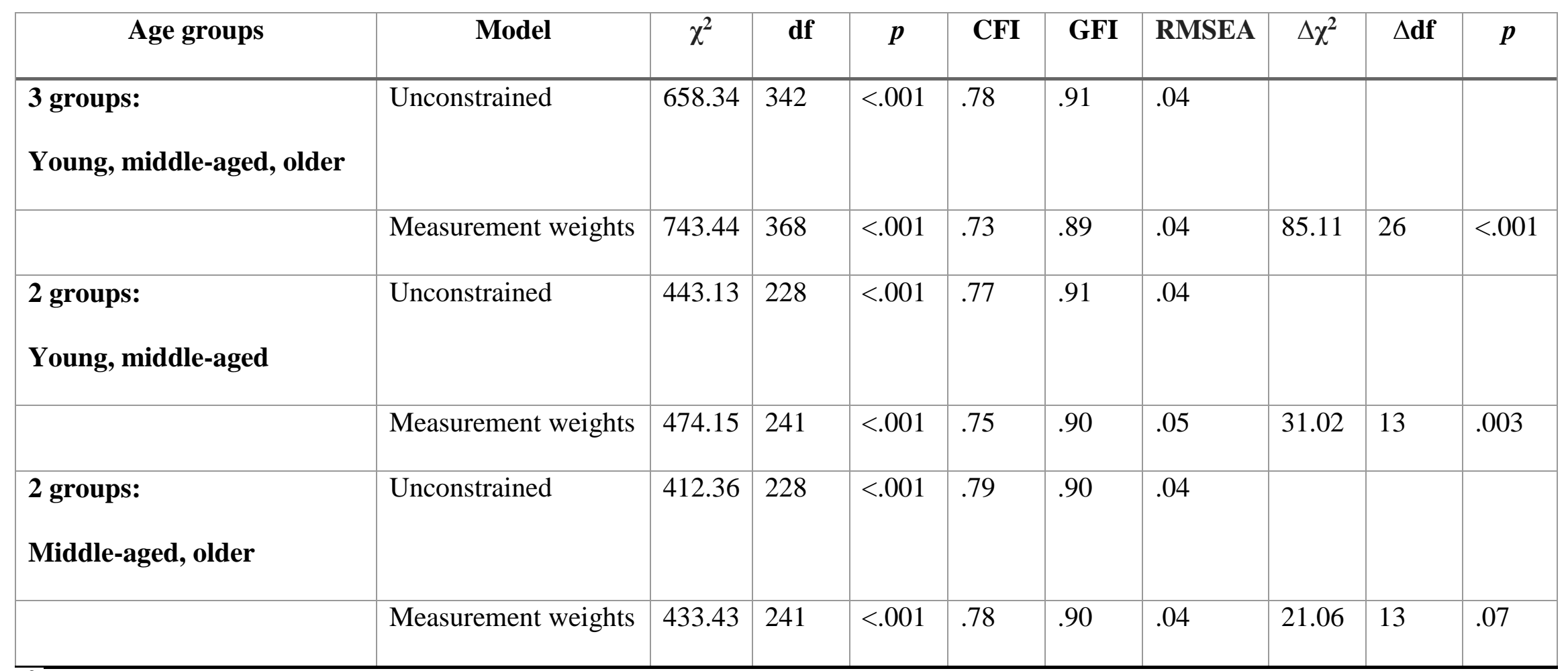

$\chi^{2}$, Chi-square test; $d f$, degree of freedom; p, p-value; CFI, comparative of fit index; GFI, goodness-of-fit index; RMSEA, root mean square error of approximation. 


\section{HEALTHY COGNITIVE AGING}

Supplemental Table 4. Percentage variance explained by each factor in Cross-domain PCAs and Typically Declining measure PCAs, conducted within each sampling decile. Cross-domain PCAs were restricted to four factors for comparison with the Cross-domain PCA for all participants.

\begin{tabular}{|c|c|c|c|c|c|}
\hline & \multicolumn{4}{|c|}{ Cross-domain PCA } & \multirow{2}{*}{$\begin{array}{c}\text { Typical- } \\
\text { declining PCA } \\
\text { Factor } 1\end{array}$} \\
\hline Decile & Factor 1 & Factor 2 & Factor 3 & Factor 4 & \\
\hline 18-27 & 16.99 & 13.47 & 12.22 & 12.01 & 36.74 \\
\hline 28-37 & 15.85 & 10.22 & 9.82 & 9.81 & 39.18 \\
\hline $38-47$ & 14.60 & 13.55 & 12.93 & 10.08 & 36.66 \\
\hline 48-57 & 14.24 & 12.67 & 12.26 & 10.35 & 35.89 \\
\hline $58-67$ & 17.89 & 10.83 & 9.87 & 9.73 & 31.89 \\
\hline 68-77 & 16.09 & 11.56 & 10.83 & 8.78 & 37.67 \\
\hline 78-87 & 14.29 & 14.11 & 12.93 & 10.32 & 34.48 \\
\hline
\end{tabular}

Supplemental Table 5. Intercorrelations of lifestyle variables. 


\section{HEALTHY COGNITIVE AGING}

\begin{tabular}{|c|c|c|c|c|}
\hline Variable & Age & Education & $\begin{array}{c}\text { Social } \\
\text { engagement }\end{array}$ & $\begin{array}{c}\text { Enrichment } \\
\text { activities }\end{array}$ \\
\hline Age & . & . & . & . \\
\hline Education & $-.25 * *$ & $\cdot$ & . & . \\
\hline Social engagement & $.35 * *$ & $-.09 *$ & . & . \\
\hline Enrichment activities & $-.17 * *$ & $.33^{* *}$ & .02 & . \\
\hline
\end{tabular}

$* p<.05 ; * * p<.01$

Supplemental Table 6. Regression analyses examining significant age interactions from regressions including all participants (see Table 4). Regressions were conducted within age groups with Cross-domain and Typically Declining factor scores regressed on lifestyle measures with age and gender covariates. Standardized $\beta$ values are reported, as well as explained variance $\left(R^{2}\right)$ and $F$ values for each model. 
HEALTHY COGNITIVE AGING

\begin{tabular}{|l|l|l|l|l|l|l|l|}
\hline & Gender & Age & Education & Social & Enrichment & $\mathbf{R}^{2}$ & $\mathbf{F}$ \\
& & & & engagement & activities & & \\
\hline
\end{tabular}

\begin{tabular}{|l|l|l|l|l|l|l|l|}
\hline Factor 1: Fluid abilities \\
\hline Young & .01 & $-.31^{* *}$ & $.18^{*}$ & $-.24 * *$ & $.21^{* *}$ & .33 & $12.77^{* *}$ \\
\hline Middle-aged & .05 & $-.43^{* *}$ & .16 & .01 & .15 & .25 & $6.82^{* *}$ \\
\hline Older & -.04 & $-.38^{* *}$ & $.25^{*}$ & .09 & .12 & .23 & $4.98^{* *}$ \\
\hline
\end{tabular}

Factor 2: Naming

\begin{tabular}{|l|c|c|c|c|c|c|c|}
\hline Young & .03 & $.22^{*}$ & .04 & .14 & -.09 & .10 & $2.84^{\dagger}$ \\
\hline Middle-aged & .09 & -.18 & .18 & .11 & -.04 & .09 & 1.95 \\
\hline Older & .08 & $-.24^{*}$ & -.07 & -.07 & .05 & .09 & 1.58 \\
\hline
\end{tabular}

Factor 3: Crystallized Abilities

\begin{tabular}{|l|c|c|c|c|c|c|c|}
\hline Young & -.13 & $.21 *$ & $.31 * *$ & -.13 & $.17 *$ & .20 & $6.68 * *$ \\
\hline Middle-aged & .03 & .15 & $.47 * *$ & -.06 & .14 & .30 & $8.45^{* *}$ \\
\hline Older & $.18 *$ & $.22 * *$ & $.75 * *$ & -.12 & -.09 & .59 & $23.80 * *$ \\
\hline
\end{tabular}

${ }^{*} p<.05 ;{ }^{\dagger} p<.02$ (Bonferroni correction); $* * p<.01$ 


\section{HEALTHY COGNITIVE AGING}

Supplemental Figure 1. Cognitive measures in each sampling decile grouped by cognitive domains. The values of measures plotted were aligned so that higher values represent better performance. 


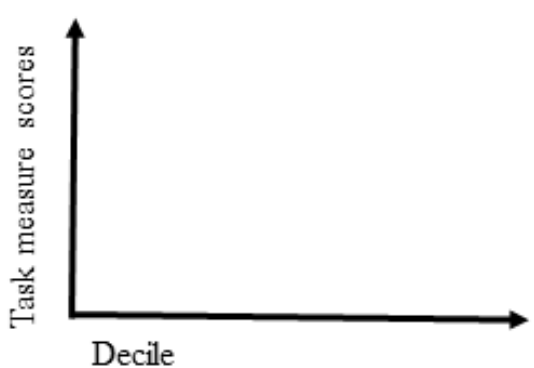

Emotion
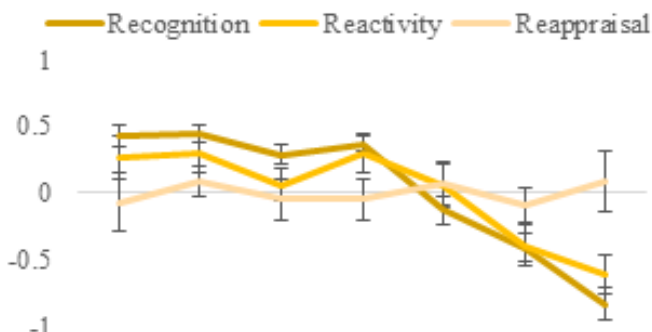

$-1.5$

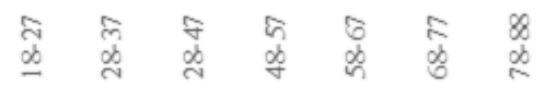$$
\text { Motor }
$$
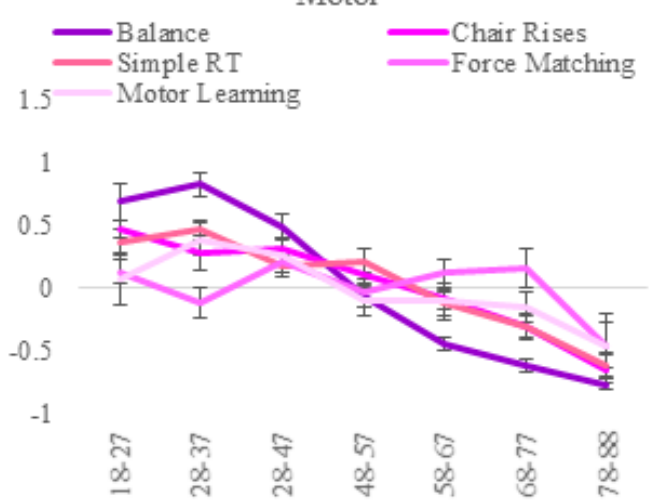

Face Recognition

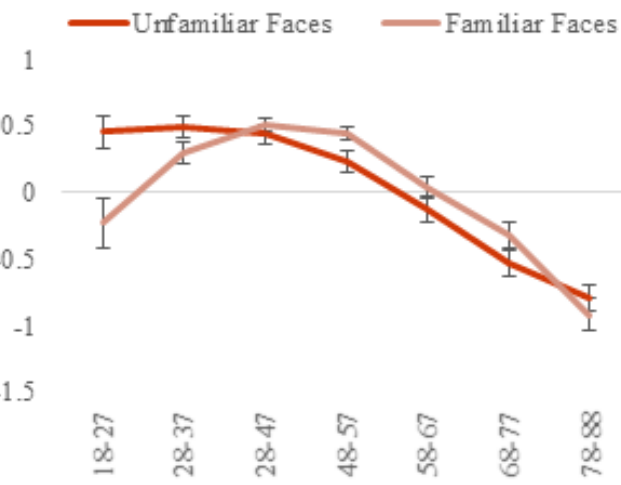

Attention

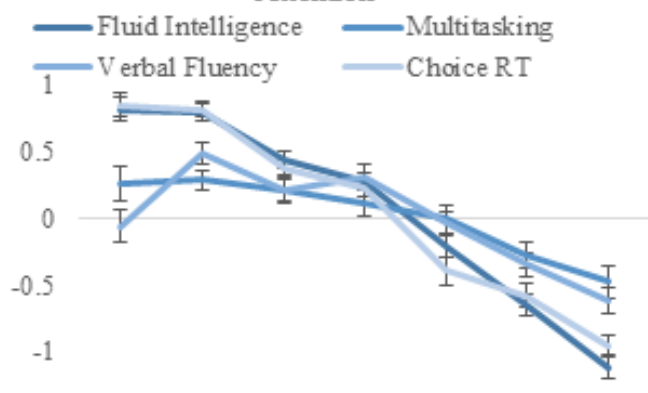

$-1.5$

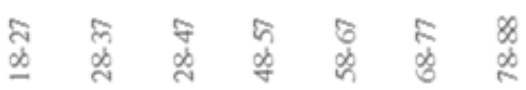
Memory

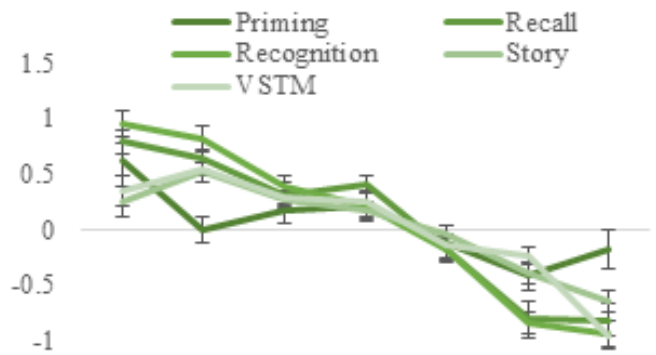

$-1.5$

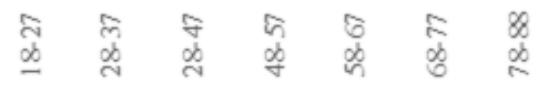
Language

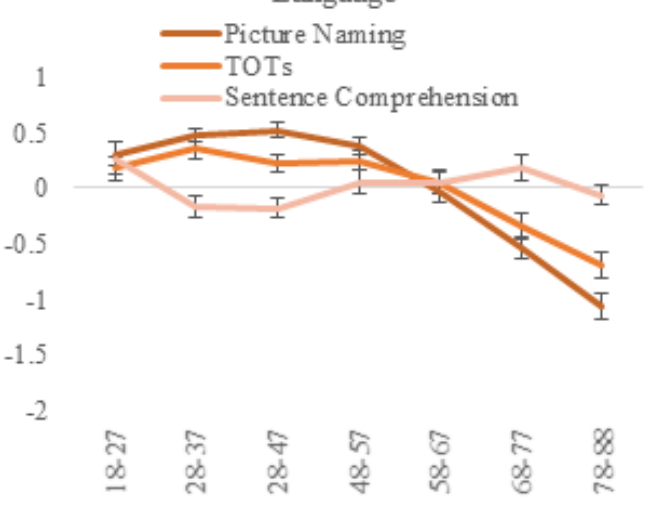

Crystallized Knowledge

Spot the Word - Proverbs

1

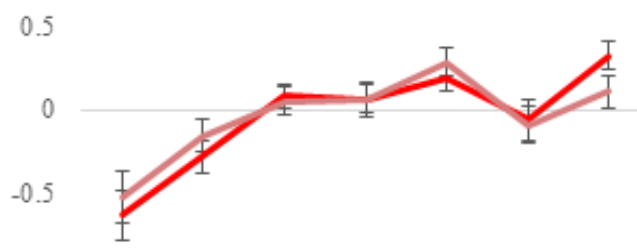

$-1$ 
Lai, K., \& Green, S. B. (2016). The Problem with Having Two Watches: Assessment of Fit When RMSEA and CFI Disagree. Multivariate Behavioral Research, 51(2-3), 220-239. https://doi.org/10.1080/00273171.2015.1134306 